\title{
Electrospun $\mathrm{Fe}_{2} \mathrm{O}_{3}$ Entrenched $\mathrm{SiO}_{2}$ Supported $\mathrm{N}$ and $\mathrm{S}$ Dual Incorporated $\mathrm{TiO}_{2}$ Nanofibers Derived from Mixed Polymeric Template/Surfactant: Enriched Mesoporosity within Nanofibers, Effective Charge Separation, and Visible Light Photocatalysis Activity
}

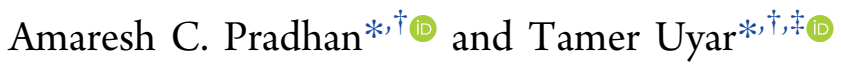 \\ ${ }^{\dagger}$ Institute of Materials Science \& Nanotechnology, Bilkent University, Ankara, 06800, Turkey \\ ${ }^{\ddagger}$ Department of Fiber Science and Apparel Design, College of Human Ecology, Cornell University, Ithaca, New York 14853, United \\ States
}

Supporting Information

ABSTRACT: The $\alpha-\mathrm{Fe}_{2} \mathrm{O}_{3}$ promoted and $\mathrm{SiO}_{2}$ supported $\mathrm{N}$ and $\mathrm{S}$ dual incorporated $\mathrm{TiO}_{2}$ nanofibers (FeSiNST NFs) along with neat oxide NFs have been synthesized by electrospinning via sol-gel. The keen approach is that mixed polyvinylpyrrolidone (PVP) as template and cetyltrimethylammonium bromide (CTAB) as surfactant are responsible for the creation of mesoporosity within NFs.

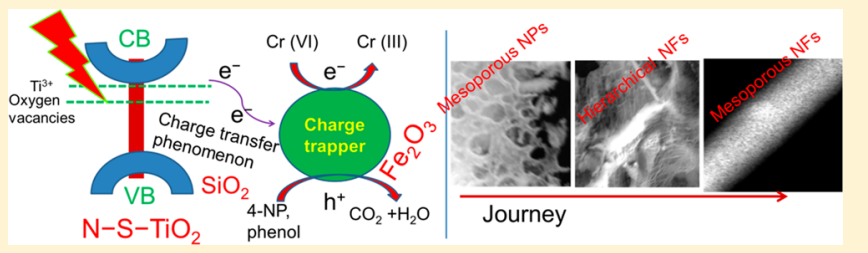
The photoluminescence (PL) spectrum and UV-visible diffuse reflectance spectroscopic (DRS) result revealed the role of $\alpha$ $\mathrm{Fe}_{2} \mathrm{O}_{3}$ as catalytic promoter in FeSiNST NFs by suppressing electron-hole $\left(\mathrm{e}^{-}-\mathrm{h}^{+}\right)$recombination, red shifting, and oxygen vacancies $\left(\mathrm{O}_{\mathrm{vs}}\right)$. The design of FeSiNST NFs by combining with $\mathrm{SiO}_{2}$ as catalytic support and $\mathrm{N}$ and $\mathrm{S}$ as visible light absorbers in $\mathrm{TiO}_{2}$, beautifies the present study. The high photocurrent $\left(3.2 \mathrm{~mA} / \mathrm{cm}^{2}\right)$, high $E_{\mathrm{fb}}$ value $(-1.0 \mathrm{~V})$, and low $R_{\mathrm{ct}}$ value $(\sim 74 \Omega)$ support the enhanced photocatalysis (photoreduction and photodegradation) by FeSiNST in visible light. Charge transfer phenomena, $\mathrm{O}_{\mathrm{vs}}$, mesoporosity, and separation of $\mathrm{e}^{-}-\mathrm{h}^{+}$are the vital factors for an effective photocatalysis achievement.

\section{INTRODUCTION}

The fabrication and nanodesign of photocatalyts with semiconductor property have attracted momentous attention due to their superior performance in pollutant remediation. ${ }^{1,2}$ Phenol, 4-nitrophenol (4-NP), and heavy metal ions such as $\mathrm{Cr}(\mathrm{IV})$ are noxious pollutants which are produced from the chemical industry. ${ }^{3-5}$ These above-mentioned pollutants have detrimental influence toward whole ecosystem because they are poisonous and carcinogenic. ${ }^{6}$ Researchers have utilized various nanodesigned materials such as nanorods, nanoparticles, nanotubes, nanowires, and nanoflowers for photocatalytic removal of pollutants and toxic elements. This is because nanodesigned materials have unique optical properties, such as sharp light-harvesting property and wide surface to volume ratio, and distinctive textural properties, such as surface area $\left(S_{\mathrm{A}}\right){ }^{7-10}$ Larger charge momentum, grain limits, swift ion distribution, and smart light absorption are the key properties which increase the great deal of attention in one-dimensional (1D) nanodesigned materials. ${ }^{11,12}$ Metal oxide nanofibers (NFs) having 1D structure fabricated by electrospinning process have remarkable features such as mesoporosity, great surface area to volume ratio, and proficient catalytic support. $^{2,13,14}$ Electrospun anatase $(\sim 3.2 \mathrm{eV}) \mathrm{TiO}_{2} \mathrm{NFs}$, an example of metal oxide NFs, have been used as a photocatalyst and sensor. This is due to their semiconductor property, long- range photoresponse in the UV region, nontoxicity, and cost effectiveness. ${ }^{15,16}$ It has been noted that $\mathrm{TiO}_{2}$ NFs fabricated by electrospinning are more competent compared to $\mathrm{TiO}_{2}$. Facile $\mathrm{e}^{-}-\mathrm{h}^{+}$momentum within the grain is an important factor for $\mathrm{e}^{-}$and $\mathrm{h}^{+}$separation. ${ }^{17}$ Hence, researchers are enthusiastic in their research of designing and modifying $\mathrm{TiO}_{2}$ NFs materials toward visible light action. Visible light response photocatalysts have many advantages over UV light. These are including costeffectiveness, ease of handling, green approach, and reaction fitness.

The design and development of anatase $\mathrm{TiO}_{2}$ NFs is essential in order to make visible light active photocatalysts toward photodegradation of 4-NP and phenol, and photoreduction of $\mathrm{Cr}(\mathrm{VI})$. Hence, the following strategic modifications will fulfill our target. These are (i) creation of mesoporosity within $\mathrm{TiO}_{2} \mathrm{NFs}$ as base photocatalyst, (ii) $\mathrm{N}$ and $\mathrm{S}$ dual incorporation as a visible light absorber, (iii) modification of $\mathrm{Fe}_{2} \mathrm{O}_{3}$ as a promoter, (iv) introduction of $\mathrm{SiO}_{2}$ as a mesoporous catalytic support, and (v) mixing all the above ingredients to form a stable mesoporous FeSiNST NFs

Received: February 19, 2019

Revised: $\quad$ May 27, 2019

Accepted: June 24, 2019

Published: June 24, 2019 
photocatalyst. Mesoporosity and NFs morphology have great impact in photocatalysis applications. ${ }^{13,14}$ This is because NFs morphology enables easy movement of the $\mathrm{e}^{-}$and $\mathrm{h}^{+}$on the catalyst surface, whereas mesoporosity enhances the $S_{\mathrm{A}}$ and surface reactive sites. Moreover, mesoporosity and NFs enhance the light absorption property and charge transport ability. Textural properties such as mesoporosity, NFs morphology, and $S_{\mathrm{A}}$ have great importance for the construction of a photocatalyst. The electrospinning route may provide a better option to achieve the mesoporosity, $S_{A}$, and NFs morphology within $\mathrm{TiO}_{2}\left(\mathrm{TiO}_{2}\right.$ NFs). The electrospinning route provides a better platform to generate NFs and porous morphology by including an apposite template, surfactant, and other additives. ${ }^{18,19}$ Hence the design and modification of the $\mathrm{TiO}_{2}$ toward mesoporosity within NFs morphology by applying a suitable mixture of template (polyvinylpyrrolidone, PVP) and surfactant (cetyltrimethylammonium bromide, $\mathrm{CTAB}$ ) will be the novel approach. It has been studied that a mixture of $\mathrm{N}$ and $\mathrm{S}$ into the $\mathrm{TiO}_{2}$ performs a bathochromic property. ${ }^{20}$ This is the main reason that researchers are interested to incorporate $\mathrm{N}$ and $\mathrm{S}$ into metal oxides for making visible light response photocatalysts. Hence, $\mathrm{N}$ and $\mathrm{S}$ dual incorporation will make the long-range light absorption property, i.e., red shifting which is due to induction of $\mathrm{N} 2 \mathrm{p}$ and $\mathrm{S} 2 \mathrm{p}$ states in the lattice of the metal oxide. ${ }^{20,21}$ Thus, $\mathrm{N}$ and $\mathrm{S}$ dual incorporation into a single metal oxide semiconductor like $\mathrm{TiO}_{2}$ will act as a visible light response photocatalyst. In the photocatalysis process the quick $\mathrm{e}^{-}-\mathrm{h}^{+}$ recombination is an adverse situation which inhibits the progress of photocatalysis reaction. Hence, in order to make an efficient photocatalyst, a suitable charge-deficient center is essential to suppress the $\mathrm{e}^{-}-\mathrm{h}^{+}$recombination. $\alpha$-Iron oxide $\left(\alpha-\mathrm{Fe}_{2} \mathrm{O}_{3}\right)$ has attracted notable attention due to its stability, cost effectiveness, nonpoisonous property, environmental sociability, suitable band gap range $(2.0-2.2 \mathrm{eV})$, and positive valence band edge potential. The advantages regarding the introduction of $\alpha-\mathrm{Fe}_{2} \mathrm{O}_{3}\left(\mathrm{Fe}^{3+}\right)$ within $\mathrm{N}-\mathrm{S}-\mathrm{TiO}_{2}$ (NST) are as follows:

(i) It possesses $3 \mathrm{~d}^{5}$ (half-filled) electronic configuration.

(ii) The ionic radius of $\mathrm{Fe}^{3+}(0.064 \mathrm{~nm})$ is nearly similar to the ionic radius of $\mathrm{Ti}^{4+}, 0.068 \mathrm{~nm}, 22$ and the resulting $\mathrm{Fe}^{3+}$ may have the ability to combine into the $\mathrm{TiO}_{2}$ structure through a substitutional and interstitial approach.

(iii) $\mathrm{Fe}^{3+}$ may perform as a charge trapping center within the NST lattice which is because of the charge transfer transition and $d-d$ transition. This process may approve the suppressing of $\mathrm{e}^{-}-\mathrm{h}^{+}$recombination and encompassing the photocatalysis activity.

(iv) Combining of metal oxide $\left(\alpha-\mathrm{Fe}_{2} \mathrm{O}_{3}\right)$ as a promoter in the form of $\mathrm{Fe}^{3+}$ in NST weakens the bonding of adjacent oxygen atoms. This will result in the creation of $\mathrm{O}_{\mathrm{vs}}$ due to the release of oxygen atoms from the lattice. ${ }^{22}$

Hence, adaptation of $\alpha-\mathrm{Fe}_{2} \mathrm{O}_{3}$ as a catalytic promoter within the NST NFs may achieve our proficient photocatalysis strategy and decrease the $\mathrm{e}^{-}-\mathrm{h}^{+}$recombination. In order to increase/distribute the catalyst reactive sites, an appropriate catalytic support is required. Mesoporous silica based materials have been used as catalyst supports in many photocatalysis applications because of high textural properties such as large $S_{\mathrm{A}}$, wide $P_{\mathrm{V}}$, and narrow pore size $\left(P_{\mathrm{S}}\right)^{23,24}$ Hence, amendment of $\mathrm{SiO}_{2}$ into the framework of NST lattice will offer the vital catalytic support to the semiconductor $\alpha-\mathrm{Fe}_{2} \mathrm{O}_{3}$ and $\mathrm{TiO}_{2}$. Thus, nanodesign of $\alpha-\mathrm{Fe}_{2} \mathrm{O}_{3}$ as promoter and $\mathrm{SiO}_{2}$ as support within NST (FeSiNST) having a mesoporosity within the NFs morphology could be able to enhance visible light absorption and diminish the recombination of $\mathrm{e}^{-}-\mathrm{h}^{+}$ which may lead to an efficient $\mathrm{Cr}(\mathrm{VI})$ photoreduction, and 4$\mathrm{NP}$ and phenol photodegradation.

Here, we describe the synthesis and design of mesoporous photocatalysts such as $\mathrm{TiO}_{2} \mathrm{NFs}, \mathrm{SiO}_{2}$ NFs, NST NFs, and FeSiNST NFs by the electrospinning via sol-gel route. Mixed PVP and CTAB have taken the important role in the synthesis of the aforesaid NFs samples. The mechanistic pathway for the formation of mesoporosity within NFs has also been explored. The mechanism of the photoreduction of $\mathrm{Cr}(\mathrm{VI})$ and photodegradation of 4-NP and phenol has been included. The role of the semiconductor $\alpha-\mathrm{Fe}_{2} \mathrm{O}_{3}$ as a charge trapping center/promoter, $\mathrm{N}$ and $\mathrm{S}$ as visible light absorber, $\mathrm{TiO}_{2}$ as base semiconductor photocatalyst, and $\mathrm{SiO}_{2}$ as catalyst support is enhancing the photocatalysis activity in the FeSiNST NFs by separation of $\mathrm{e}^{-}$and $\mathrm{h}^{+}$. The synergetic action of $\mathrm{N}, \mathrm{S}, \mathrm{TiO}_{2}, \alpha-$ $\mathrm{Fe}_{2} \mathrm{O}_{3}$, and $\mathrm{SiO}_{2}$ in the mesoporous FeSiNST NFs displays the maximum photocatalysis performance over neat NFs. The mesoporosity within NFs, high $S_{\mathrm{A}}$ optical properties, and charge transfer phenomena have key roles for an enhanced photocatalysis performance.

\section{EXPERIMENTAL SECTION}

2.1. Materials. The chemicals involved in the research were of analytical quality. These were used directly in the reaction without purification. Titanium isopropoxide (Ti$\left.(\mathrm{iPr})_{4}\right)$, tetraethyl orthosilicate (TEOS, $\left.\mathrm{Si}\left(\mathrm{OC}_{2} \mathrm{H}_{5}\right)_{4}\right)$, PVP $\left(M_{\mathrm{w}}=1300000 \mathrm{~g} / \mathrm{mol}\right)$, and potassium iodide (KI) were from Aldrich, whereas iron chloride $\left(\mathrm{Fe}(\mathrm{III}) \mathrm{Cl} \cdot 6 \mathrm{H}_{2} \mathrm{O}\right)$ was from Sigma-Aldrich. Thiourea $\left(\mathrm{CH}_{4} \mathrm{~N}_{2} \mathrm{~S}\right), \mathrm{CTAB}, 4$-nitrophenol (4-NP), phenol, potassium dichromate $\left(\mathrm{K}_{2} \mathrm{Cr}_{2} \mathrm{O}_{7}\right)$, and $p$-benzoquinone used were from Alfa Aesar.

2.2. Fabrication of Mesoporous $\mathrm{TiO}_{2}$ and $\mathrm{SiO}_{2} \mathrm{NFs}$ by Electrospinning via Sol-Gel. The electrospinning via solgel route was introduced to synthesize $\mathrm{TiO}_{2} \mathrm{NFs}$ and $\mathrm{SiO}_{2}$ NFs. For $\mathrm{TiO}_{2}$ NFs synthesis, $1 \mathrm{~mL}$ of titanium isopropoxide was added in $8 \mathrm{~mL}$ of isopropanol in a beaker. Then, PVP (1.0 $\mathrm{g}$ ) was inserted and stirred well for $2 \mathrm{~h}$. Afterward, $0.15 \mathrm{~g}$ of $\mathrm{CTAB}$ mixed with $3 \mathrm{~mL}$ of $\mathrm{H}_{2} \mathrm{O}$ was added into the above solution. Lastly, acetic acid $(2.5 \mathrm{~mL})$ was mixed into the solution and stirred for $12 \mathrm{~h}$. The gel was filled into a plastic syringe $(3 \mathrm{~mL})$ with a needle diameter of $0.4 \mathrm{~mm}$ and connected to a syringe pump (KDS101, KD Scientific, USA). The gel rate of flow was sustained at $0.8 \mathrm{~mL} / \mathrm{h}$ with a supply of an $11.5 \mathrm{kV}$ electric field. The voltage was delivered by Spellman, USA. Aluminum foil was connected in the electric field to collect the sample. The temperature and humidity were maintained at $23{ }^{\circ} \mathrm{C}$ and $18 \%$, respectively. The synthesized $\mathrm{TiO}_{2} / \mathrm{PVP} / \mathrm{CTAB}$ mixed NFs were calcined at $450{ }^{\circ} \mathrm{C}$ for $5 \mathrm{~h}$, and finally mesoporous $\mathrm{TiO}_{2} \mathrm{NFs}$ were produced. The mesoporous $\mathrm{SiO}_{2} \mathrm{NFs}$ were prepared with exactly the same method as for $\mathrm{TiO}_{2} \mathrm{NFs}$, only by adding $1 \mathrm{~mL}$ of TEOS as the source of silica. The mesoporous $\mathrm{SiO}_{2} \mathrm{NFs}$ were produced after removal of PVP and $\mathrm{CTAB}$ from $\mathrm{SiO}_{2} / \mathrm{PVP} / \mathrm{CTAB}$ mixed NFs at the calcination temperature $450{ }^{\circ} \mathrm{C}$ for $5 \mathrm{~h}$.

2.3. Electrospinning via Sol-Gel Fabrication of Mesoporous NST NFs, FeSiNST NFs, FeSiNST HNFs, and Electrospraying FeSiNST MNPs. In the beginning, 1.5 $\mathrm{g}$ of PVP was mixed with $12 \mathrm{~mL}$ of isopropanol in a beaker. In a separate beaker $0.15 \mathrm{~g}$ of CTAB was mixed in $3 \mathrm{~mL}$ of $\mathrm{H}_{2} \mathrm{O}$. Both solutions were mixed well along with $0.5 \mathrm{~g}$ of thiourea 
introduced as a source of $\mathrm{N}$ and $\mathrm{S}$. Afterward, titanium isopropoxide $(2 \mathrm{~mL})$ was mixed in and stirred in order to get a sol. Lastly, acetic acid $(2 \mathrm{~mL})$ was mixed as a solution stabilizer to maintain the proper viscosity for the electrospinning via sol-gel process. The resultant mixture was stirred for $12 \mathrm{~h}$. The mild gray colored gel solution was set for exactly the same electrospinning via sol-gel procedure as for the $\mathrm{TiO}_{2}$ NFs. The mild gray color is because of the presence of $\mathrm{S}$. Moreover, the mesoporous $\mathrm{N}$ and $\mathrm{S}$ dual incorporated $\mathrm{TiO}_{2} \mathrm{NFs}$ (NST $\mathrm{NFs}$ ) were formed after calcination $\left(450{ }^{\circ} \mathrm{C}, 5 \mathrm{~h}\right)$.

Similarly, mesoporous $\alpha-\mathrm{Fe}_{2} \mathrm{O}_{3}$ promoted and $\mathrm{SiO}_{2}$ supported with $\mathrm{N}$ and $\mathrm{S}$ mixed $\mathrm{TiO}_{2}$ nanofibers (mesoporous FeSiNST NFs) were fabricated by a three-pot system. In the first pot, $1.5 \mathrm{~g}$ of PVP was mixed well in $12 \mathrm{~mL}$ of isopropanol. Subsequently, CTAB solution ( $0.15 \mathrm{~g}$ of CTAB mixed with 3 $\mathrm{mL}$ of $\mathrm{H}_{2} \mathrm{O}$ ) was added into the above solution. Then, $0.5 \mathrm{~g}$ of thiourea and titanium isopropoxide $(2 \mathrm{~mL})$ was mixed. Next, acetic acid $(3.5 \mathrm{~mL})$ was added and stirred for getting a gray sol. This proves that $\mathrm{N}$ and $\mathrm{S}$ were incorporated into the $\mathrm{Ti}-$ $\mathrm{O}-\mathrm{Ti}$ framework. In the second pot, $0.15 \mathrm{~g}$ of $\mathrm{CTAB}$ was mixed in $\mathrm{H}_{2} \mathrm{O}(5 \mathrm{~mL})$ with continuous stirring. TEOS $(0.5$ $\mathrm{mL}$ ) was added and stirred for $1 \mathrm{~h}$. In the third pot, $0.6 \mathrm{~g}$ of $\mathrm{Fe}$ (III) $\mathrm{Cl} \cdot 6 \mathrm{H}_{2} \mathrm{O}$ was added to $4 \mathrm{~mL}$ of isopropanol and stirred for $2 \mathrm{~h}$. All of the three-pot reaction substances were mixed and stirred for $6 \mathrm{~h}$ to get a gel. The final gel filled a plastic syringe $(3 \mathrm{~mL})$ and followed the electrospinning process. The syringe pump with a flow rate of $0.5 \mathrm{~mL} / \mathrm{h}$ was set up to regulate the gel flow. A fixed $15 \mathrm{kV}$ (Spellman) was applied to continue the power supply. Finally, mesoporous FeSiNST NFs were formed by calcination at $450{ }^{\circ} \mathrm{C}$ for $5 \mathrm{~h}$. The weights of $\mathrm{Ti}, \mathrm{Fe}, \mathrm{Si}, \mathrm{S}$, and $\mathrm{N}$ present in the FeSiNST NFs are 0.540, $0.142,0.074,0.053$, and $0.038 \mathrm{~g}$, respectively.

The FeSiNST hierarchical nanofibers were designated as FeSiNST HNFs. The synthesis procedure was like that of mesoporous FeSiNST NFs. Here the only difference was that PVP was taken as a template instead of mixed PVP and CTAB (template/surfactant). The material was calcined at $450{ }^{\circ} \mathrm{C}$ for $5 \mathrm{~h}$ and formed FeSiNST HNFs. The mesoporous FeSiNST nanoparticles (FeSiNST MNPs) were fabricated by an electrospraying process. The $\mathrm{CTAB}$ is used as a surfactant instead of mixed PVP and CTAB. The other precursors were similar to those in the synthesis of mesoporous FeSiNST NFs, but the difference was the electrospraying process. Finally, FeSiNST MNPs were formed after calcination at $450{ }^{\circ} \mathrm{C}$ in 5 h. Scheme 1 depicts the scanning electron microscopy (SEM)/ scanning transmission electron microscopy (STEM) images of the FeSiNST MNPs, FeSiNST HNFs and mesoporous FeSiNST NFs by taking CTAB as surfactant, PVP as template, and PVP and CTAB as mixed template/surfactant, respectively. The creation of mesoporosity within NFs (FeSiNST NFs) is because of the mixture of PVP and CTAB as template/ surfactant. But neat PVP and CTAB had important roles for the fabrication of FeSiNST HNFs and FeSiNST MNPs, respectively.

2.4. Characterization. The textural properties such as $S_{\mathrm{A}}$ pore size $\left(P_{\mathrm{S}}\right)$, and pore volume $\left(P_{\mathrm{V}}\right)$ of the NFs were calculated from $\mathrm{N}_{2}$ adsorption-desorption method at $-196{ }^{\circ} \mathrm{C}$ (liquid $\mathrm{N}_{2}$ ). The experiment was done with a Quantachrome Instrument Autosorb (iQ2). A PANalyticalX'Pert Pro multipurpose X-ray diffractometer (XRD) was analyzed to check the crystal arrangement and phase of the NFs photocatalysts. The $\mathrm{XRD}$ of the sample was measured in the range $2 \theta=10-80^{\circ}$ with $\mathrm{Cu} \mathrm{K} \alpha(1.5418 \AA)$ radiation. Field emission scanning
Scheme 1. Electrosprayed Mesoporous FeSiNST MNPs (Surfactant, CTAB Only), Electrospun FeSiNST HNFs (Template, PVP Only), and Mesoporous FeSiNST NFs (Template/Surfactant, PVP/CTAB Mixture) Obtained after Calcination at $450{ }^{\circ} \mathrm{C}$ for $5 \mathrm{~h}$

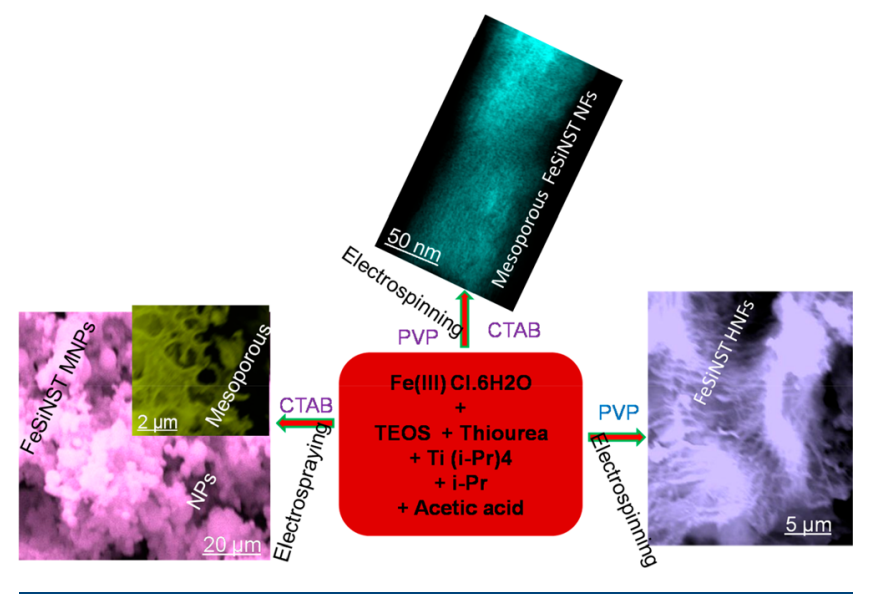

electron microscopy (FE-SEM) was analyzed with a Quanta 200 FEG, FEI, to check the morphology of the surface. A Tecnai G2 F30, FEI (high resolution transmission electron microscopy; HR-TEM) was employed to analyze the morphology and selected area electron diffraction (SAED) of the NFs. STEM with energy-dispersive X-ray spectroscopy (STEM-EDX) was applied to study the composition of the metal/elements in the form of oxides within the NFs. A Varian Cary 100, a UV-visible spectrophotometer, was used to record the absorption spectra of the synthesized materials. A Cary 500 was used to measure the UV-vis-near-infrared (NIR) diffuse reflectance spectroscopy (DRS). An FL-1057 TCSPC was used to analyze photoluminescence (PL) spectra. The spectra were measured with an excitation wavelength at $390 \mathrm{~nm}$. A Thermo K-Alpha monochromated X-ray photoelectron spectrometer (XPS) was utilized to calculate the binding energy (BE) through XPS spectra with the excitation energy $h \nu=$ $1484.6 \mathrm{eV}$. The BEs of the NFs materials were plotted by using carbon $(\mathrm{BE}=284.8 \mathrm{eV})$ as reference.

2.5. Photocatalysis Activity in Visible Light. The photocatalysis process, i.e., photoreduction of $\mathrm{Cr}(\mathrm{VI})$, progressed by utilizing $10 \mathrm{~mL}$ of $\mathrm{K}_{2} \mathrm{Cr}_{2} \mathrm{O}_{7}\left(40 \mathrm{mg} \cdot \mathrm{L}^{-1}\right)$ solution, catalyst dose $\left(1 \mathrm{mg} \cdot \mathrm{mL}^{-1}\right)$ at $\mathrm{pH} 4$ within $80 \mathrm{~min}$. Before photoreduction, the reaction solution with photocatalysts was stirred for $35 \mathrm{~min}$ in order to achieve equilibrium. A Mettler Toledo $\mathrm{pH}$ meter was used to measure the $\mathrm{pH}$. Proper concentrations of nitric acid and $\mathrm{NH}_{3}$ were mixed dropwise to adjust the $\mathrm{pH}$ of the solution. The suspension was set in a reactor (Osram, sunlight simulation) and exposed in visible light with a power of $300 \mathrm{~W}$. After reaction, the catalyst was separated by filtration. The resultant product was inspected by a UV-vis spectrophotometer with a $350 \mathrm{~nm}$ absorption band.

Phenol and 4-NP photodegradation was examined by involving $30 \mathrm{mg} \cdot \mathrm{L}^{-1}$ concentrations of each pollutant. Both (phenol and 4-NP) solutions with presently synthesized NFs photocatalysts were stirred $(40 \mathrm{~min})$ individually to get equilibrium. The reaction proceeded by taking $10 \mathrm{~mL}$ of phenol and 4-NP separately with $1 \mathrm{mg} \cdot \mathrm{mL}^{-1}$ photcatalyst dose at $\mathrm{pH} 6$ during $100 \mathrm{~min}$. The $\mathrm{pH}$ analyzer, light source, and UV-vis spectrophotometer were used in the photodegradation 

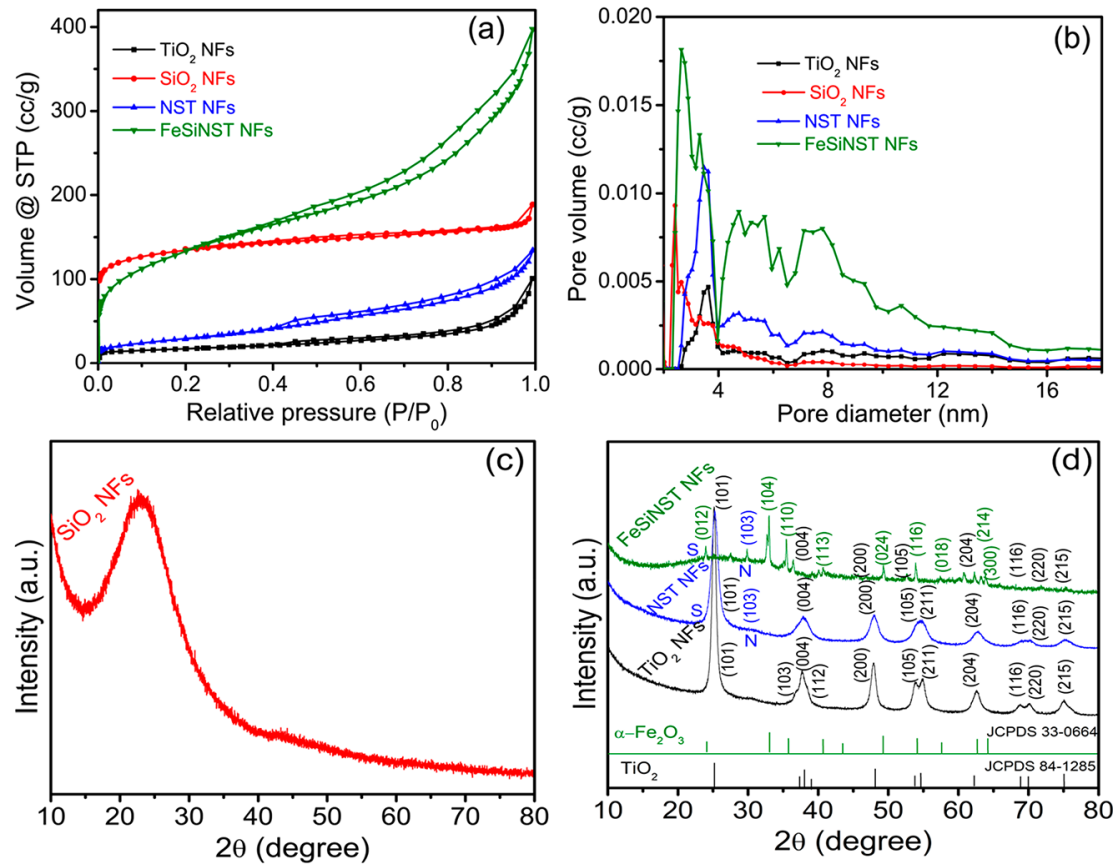

Figure 1. (a) $\mathrm{N}_{2}$ sorption isotherm, (b) pore size $\left(P_{\mathrm{S}}\right)$, and (c) XRD pattern of mesoporous $\mathrm{SiO}_{2} \mathrm{NFs}$. (d) XRD patterns of TiO 2 NFs, $\mathrm{NST}^{\mathrm{N} F s}$, and FeSiNST NFs.

process, similar to the photoreduction of $\mathrm{Cr}(\mathrm{VI})$. Finally, the maximum absorbances of phenol $(210 \mathrm{~nm})$ and 4-NP (400 $\mathrm{nm}$ ) were measured. The recyclability study of $\mathrm{Cr}(\mathrm{VI})$ reduction and 4-NP degradation by mesoporous FeSiNST NFs was carried out up to the fourth run in the optimum reaction condition. After the finish of each run, the mesoporous FeSiNST NFs material was calcined at $450{ }^{\circ} \mathrm{C}$ in $5 \mathrm{~h}$ in order to remove impurity and make reborn the mesoporosity.

2.6. Trapping of Active Species. The trapping reaction proceeded by adding different scavengers in the reaction media in the presence of FeSiNST NFs, which gives an idea about active species involved in reaction. In photocatalysis (photoreduction and photodegradation) reaction, $0.1 \mathrm{mmol}$ of different scavengers such as $\mathrm{KI}$, isopropyl alcohol (IPA), $p$ benzoquinone (BQ), and dimethyl sulfoxide (DMSO) was used to check the involvement of $\mathrm{h}^{+},{ }^{\bullet} \mathrm{OH}, \mathrm{O}_{2}{ }^{--}$, and $\mathrm{e}^{-}$, respectively. The trapping reaction situation is like the photoreduction of $\mathrm{Cr}(\mathrm{VI})$, and the photodegradation of 4NP and phenol. The scavengers were mixed in reaction solution before the photocatalysis process.

2.7. Photoelectrochemical Study. The photoelectrochemical measurements were carried out by using platinum wire, $\mathrm{Ag} / \mathrm{AgCl}$ electrode, and prepared electrode as the counter electrode, reference electrode, and working electrode, respectively. Electrodes were immersed in $0.1 \mathrm{M} \mathrm{Na}_{2} \mathrm{SO}_{4}$ solution. $\mathrm{N}_{2}$ gas was used to saturate the electrolyte before electrochemical measurements. For photoelectrochemical measurement, an Ivum multichannel potentiostat with light irradiation $(\lambda=400 \mathrm{~nm})$ was used. Irradiation was executed by using a $300 \mathrm{~W}$ Xe lamp with a $400 \mathrm{~nm}$ cutoff filter.

\section{RESULTS AND DISCUSSION}

3.1. $\mathrm{N}_{2}$ Adsorption-Desorption and XRD. Figure $1 \mathrm{a}, \mathrm{b}$ depicts the $\mathrm{N}_{2}$ adsorption-desorption isotherms and the $P_{\mathrm{S}}$ distributions of NFs. All NFs photocatalysts show type IV isotherms having $\mathrm{H} 1$ and $\mathrm{H} 3$ hysteresis (Figure 1a). This type of hysteresis is the indication of mesoporosity. ${ }^{25}$ The hysteresis loops of all NFs begin with $P / P_{0}$ (relative pressure) of $0.1-0.5$. This is due to the presence of narrow mesopores, i.e., intraparticle mesoporosity or "framework porosity". The creation of mesoporosity within NFs is because of the removal of CTAB as surfactant at an optimal heat treatment at $450{ }^{\circ} \mathrm{C}$ in $5 \mathrm{~h}$. Figure $1 \mathrm{~b}$ describes the $P_{\mathrm{S}}(2-5 \mathrm{~nm})$ of the NFs materials, and the ensuing mesoporous nature of NFs. The textural properties such as $S_{\mathrm{A}}, P_{\mathrm{S}}$, and $P_{\mathrm{V}}$ of the NFs are shown in the Supporting Information (Table S1). Amazingly, the larger $S_{\mathrm{A}}$ values of $\mathrm{TiO}_{2} \mathrm{NFs}, \mathrm{SiO}_{2}$ NFs, NST NFs, and FeSiNST NFs, which are 50, 505, 110, and $300 \mathrm{~m}^{2} / \mathrm{g}$, respectively, are calculated. Hence, high $S_{\mathrm{A}}$ values of NFs photocatalysts will offer more active spots for contact with $\mathrm{Cr}(\mathrm{VI})$, and 4-NP and phenol. The greater $\mathrm{S}_{\mathrm{A}}$ of $\mathrm{SiO}_{2} \mathrm{NFs}$ $\left(505 \mathrm{~m}^{2} / \mathrm{g}\right)$ than those of other synthesized NFs is a signpost of the involvement of $\mathrm{SiO}_{2}$ in $\mathrm{FeSiNST}$ NFs. The presence of $\mathrm{SiO}_{2}$ in FeSiNST NFs aids the enhancement of the $S_{\mathrm{A}}$ of the FeSiNST NFs $\left(300 \mathrm{~m}^{2} / \mathrm{g}\right)$. This is the vibrant reason to combine $\mathrm{SiO}_{2}$ in FeSiNST NFs as a support. The $P_{\mathrm{S}}$ values of the entire NFs samples belong to the mesoporous range (Table S1). All NFs samples possess wide $P_{\mathrm{V}}$, indicating large $S_{\mathrm{A}}$ (Supporting Information). Hence, the $\mathrm{N}_{2}$ sorption isotherm provides clear information about the creation of mesoporosity and textural properties within the NFs.

Figure 1c displays the XRD pattern of the $\mathrm{SiO}_{2} \mathrm{NFs}$. The peak at $2 \theta=22.6^{\circ}$ is assigned to the amorphous $\mathrm{SiO}_{2} \cdot{ }^{26} \mathrm{XRD}$ patterns of $\mathrm{TiO}_{2}$ NFs, NST NFs, FeSiNST NFs are exposed in Figure $1 \mathrm{~d}$. In the case of mesoporous $\mathrm{TiO}_{2} \mathrm{NFs}$, the peaks at $25.1,36.9,37.6,38.5,48.8,53.8,54.8,62.7,68.6,70.1$, and $75^{\circ}$ matching with the planes (101), (103), (004), (112), (200), (105), (211), (204), (116), (220), and (215) because of the anatase $\mathrm{TiO}_{2}$ [JCPDS no. 84-1285]. For mesoporous NST NFs, the Bragg reflection angles correspond with the crystal planes of anatase $\mathrm{TiO}_{2}$, including $\mathrm{N}\left(30.1^{\circ}\right)$ for the (103) 
plane and $\mathrm{S}$ at an angle of $23^{\circ} .^{13,26}$ The less intense peak of $\mathrm{N}$ and $S$ in the respective material is because of the least quantity of $\mathrm{N}$ and $\mathrm{S}$ (dopant). The existence of $\mathrm{N}$ and $\mathrm{S}$ will be clearly visible in STEM-EDX and XPS analysis. Hence, it is proved that the $\mathrm{N}$ and $\mathrm{S}$ are incorporated in an anatase $\mathrm{TiO}_{2}$ lattice (NST NFs). The mesoporous FeSiNST NFs have crystal planes (012), (104), (110), (113), (024), (116), (214), and (300), due to the presence of $\alpha-\mathrm{Fe}_{2} \mathrm{O}_{3}$ [JCPDS no. 33-0664]. The FeSiNST NFs also include some anatase $\mathrm{TiO}_{2}$ signature along with $\mathrm{N}$ and $\mathrm{S}$, but some peaks of $\mathrm{TiO}_{2}$ are overlapped by $\alpha-\mathrm{Fe}_{2} \mathrm{O}_{3}$ peaks. The less intense peaks of FeSiNST NFs are due to the presence of the amorphous nature of $\mathrm{SiO}_{2}$. Hence, mesoporous FeSiNST NFs consists of $\alpha-\mathrm{Fe}_{2} \mathrm{O}_{3}, \mathrm{SiO}_{2}$, and $\mathrm{TiO}_{2}$ along with $\mathrm{N}$ and $\mathrm{S}$.

3.2. Morphological Study. The SEM images (Figure 2) describe the morphologies of the NFs. The variation of

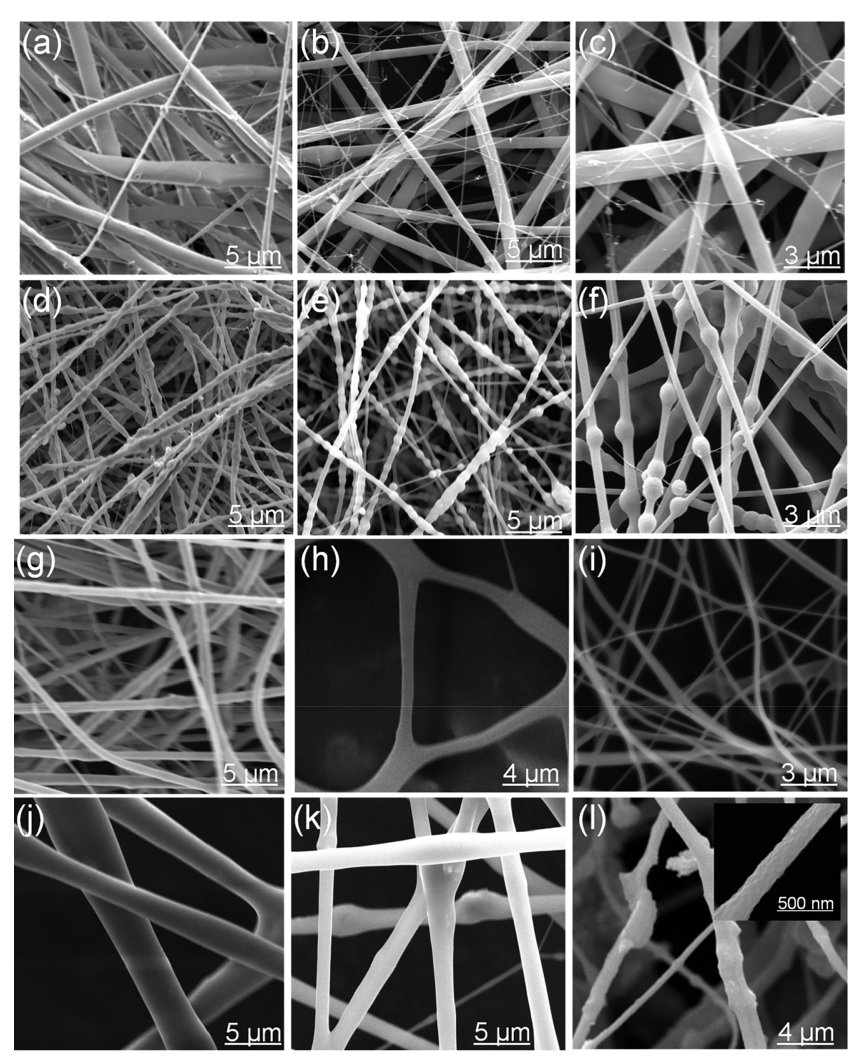

Figure 2. Representative SEM images of NFs calcined at different temperatures of 70,200 , and $450{ }^{\circ} \mathrm{C}: \mathrm{TiO}_{2} \mathrm{NFs}(\mathrm{a}-\mathrm{c}), \mathrm{SiO}_{2} \mathrm{NFs}(\mathrm{d}-$ f), NST NFs $(g-i)$, and FeSiNST NFs $(j-1)$.

temperature, i.e., before calcination $\left(70{ }^{\circ} \mathrm{C}, 5 \mathrm{~h}\right)$, intermediate temperature $\left(200{ }^{\circ} \mathrm{C}, 5 \mathrm{~h}\right)$, and calcination $\left(450{ }^{\circ} \mathrm{C}, 5 \mathrm{~h}\right)$, with respect to morphology has been examined to identify the stability of the NFs. The heat treatment of NFs at 70 and 200 ${ }^{\circ} \mathrm{C}$ is denoted as PVP and $\mathrm{CTAB}$ mixed NFs, whereas calcination at $450{ }^{\circ} \mathrm{C}$ is referred to as mesoporosity within NFs. The temperature variation of NFs has been done separately. Figure 2, parts a, b, and c, displays the SEM images of $\mathrm{TiO}_{2} \mathrm{NFs}$ at 70,200 , and $450{ }^{\circ} \mathrm{C}$, respectively. The smooth, bead-free NFs morphology having black color in Figure $2 \mathrm{a}$, b is due to the PVP and CTAB mixed $\mathrm{TiO}_{2}$ NFs. After calcination at $450{ }^{\circ} \mathrm{C}$ for $5 \mathrm{~h}$ (complete elimination of PVP and CTAB), the mesoporous $\mathrm{TiO}_{2} \mathrm{NFs}$ are obtained (Figure 2c). The mesoporosity of the NFs is not clearly visible which is due to the narrow $P_{\mathrm{S}}$. The $\mathrm{TiO}_{2}$ NFs diameters are at different temperatures are calculated and shown in Table S1. The NFs diameter is reduced gradually from $500 \pm 50$ to $210 \pm 30 \mathrm{~nm}$ with variation of temperature from 70 to $450{ }^{\circ} \mathrm{C}$. Similarly, smooth and bead-free PVP and CTAB mixed $\mathrm{SiO}_{2} \mathrm{NFs}$ are fabricated at the temperatures 70 and $200{ }^{\circ} \mathrm{C}$ (Figure $2 \mathrm{~d}, \mathrm{e}$ ). Mesoporous $\mathrm{SiO}_{2} \mathrm{NFs}$ having diameter of $180 \pm 20 \mathrm{~nm}$ are obtained when PVP and CTAB mixed $\mathrm{SiO}_{2} \mathrm{NFs}$ are calcined at $450{ }^{\circ} \mathrm{C}, 5 \mathrm{~h}$ (Figure $2 \mathrm{f}$ ). The diameter decrease of PVP and $\mathrm{CTAB}$ mixed $\mathrm{SiO}_{2} \mathrm{NFs}$ to mesoporous $\mathrm{SiO}_{2} \mathrm{NFs}$ with different temperatures is shown in Table S1. Likewise, smooth and bead-free PVP and CTAB mixed SNT NFs obtained at heat treatment at 70 and $200{ }^{\circ} \mathrm{C}$ are shown in Figure $2 \mathrm{~g}$,h. But mesoporous NST NFs having diameter of $150 \pm 20$ are obtained after calcinations of PVP and CTAB mixed SNT NFs at $450{ }^{\circ} \mathrm{C}, 5 \mathrm{~h}$ (Figure 2i). Moreover, PVP and CTAB mixed FeSiNST NFs having smooth and bead-free morphology are obtained at 70 and $200{ }^{\circ} \mathrm{C}$ (Figure 2jk). But mesoporous FeSiNST NFs having diameter of $200 \pm 20$ are fabricated, when PVP and CTAB mixed FeSiNST NFs are calcined at 450 ${ }^{\circ} \mathrm{C}$ (Figure 21). The decrease occurred gradually from 70 to $450{ }^{\circ} \mathrm{C}$ (Table S1). From SEM images for all NFs materials, the mesoporosity is not clearly seen which is due to the narrow $P_{\mathrm{S}}$ in the range $2.5-4.7$ (Table $\mathrm{S} 1$ ). From the SEM analyses, it is well-understood that mixed PVP and CTAB have a proficient role in the formation of fiber, whereas different heat treatments have an important role in the creation of mesoporosity in the framework of NFs.

To recognize the importance of mixed PVP and CTAB as a template/surfactant for the construction of mesoporosity within NFs, the FeSiNST has been synthesized separately by taking PVP and CTAB as template and surfactant, respectively. The SEM image of the electrospun FeSiNST, synthesized by only PVP as template, is shown in the Supporting Information (Figure Sla,b). A hierarchical NFs morphology is obtained which is called FeSiNST hierarchical NFs (FeSiNST HNFs).The SEM image of the FeSiNST which is synthesized by only CTAB as surfactant is pictured in Figure S1c,d. Figure S1c illustrates the nanoparticles (NPs) nature, whereas Figure S1d represents the mesoporosity. Hence, FeSiNST synthesized by CTAB is called FeSiNST mesoporous NPs (FeSiNST MNPs). From SEM images of FeSiNST HNFs and FeSiNST MNPs, it is observed that template PVP generates hierarchical NFs and $C T A B$ aids to create mesoporous NPs. For more clarification regarding role of PVP and CTAB, the $\mathrm{N}_{2}$ adsorption-desorption isotherm of FeSiNST HNFs and FeSiNST MNPs is pictured in Figure S2. Both materials showing type IV mesoporosity. But the $S_{\mathrm{A}}$ values of FeSiNST HNFs and FeSiNST MNPs are 95 and $190 \mathrm{~m}^{2} / \mathrm{g}$, respectively (Table S1). Mesoporsity is directly related to the $S_{\mathrm{A}}$, which means highly mesoporous materials have large $S_{\mathrm{A}}$ values. Hence, FeSiNST MNPs have a higher mesoporosity than FeSiNST HNFs, which leads to enhanced $S_{\mathrm{A}}$. Therefore, the decrease of all NFs diameters with the increase of temperature is owing to the gradual elimination/decomposition of PVP, whereas generation of mesoporsity is due to the decomposition of $\mathrm{CTAB}$ at high calcination temperature $\left(450{ }^{\circ} \mathrm{C}\right.$ in $\left.5 \mathrm{~h}\right)$. Conclusively, from SEM and $\mathrm{N}_{2}$ adsorption-desorption method it is well-understood that PVP is responsible for the preparation of NFs morphology, whereas CTAB is responsible for formation of mesoporosity. The combination of PVP and $\mathrm{CTAB}$ is the reason for the creation of mesoporosity within NFs. 
In order to study the morphology of the NFs material, TEM and STEM analyses have been executed (Figure 3). Figure 3a,b

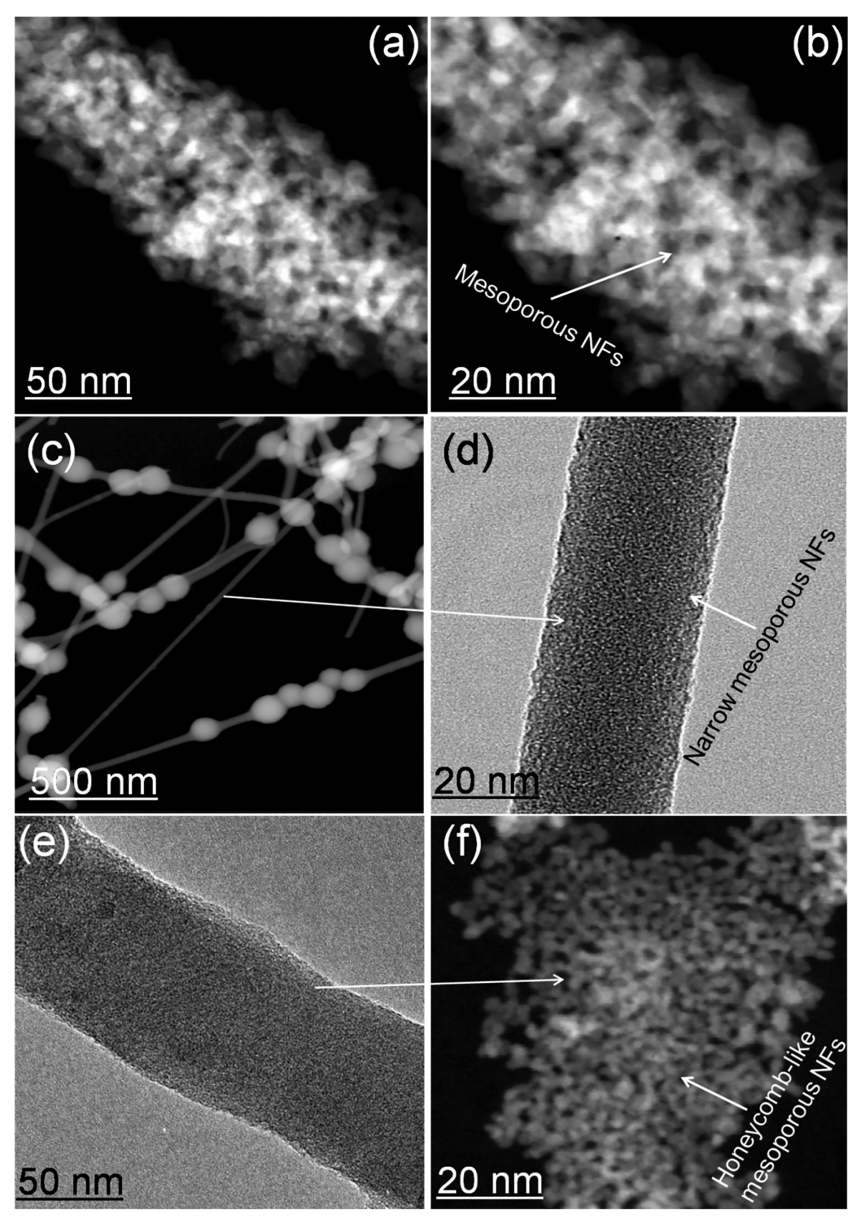

Figure 3. Representative TEM images of $(a, b)$ mesoporous $\mathrm{TiO}_{2}$ NFs, (c, d) mesoporous $\mathrm{SiO}_{2} \mathrm{NFs}$, and (e, f) mesoporous NST NFs.

depicts STEM micrographs of mesoporous $\mathrm{TiO}_{2}$ NFs. The morphology of highly porous nature (mesoporous) is observed which is consistent with the $\mathrm{N}_{2}$ adsorption-desorption study. The diameter of the NFs is $84 \pm 4 \mathrm{~nm}$ (Table S1). The architecture of the $\mathrm{TiO}_{2}$ NFs could be "mesoporosity-in- $\mathrm{TiO}_{2}$ NFs". Similarly, STEM (Figure 3c) and TEM (Figure 3d) images display the narrow mesoporous nature of NFs with NFs diameter of $72 \pm 3 \mathrm{~nm}$ and possess "mesoporosity-in- $\mathrm{SiO}_{2}$ NFs" architecture. Moreover, TEM (Figure 3e) and STEM (Figure 3f) images of the mesoporous NST NFs also retain "mesoporosity-in-SNT NFs" architecture with $95 \pm 4 \mathrm{~nm} \mathrm{NFs}$ diameter. An amazing honeycomb-like mesoporosity is obtained in Figure 3f. Hence, mesoporosity within NFs morphology in all synthesized NFs will increase the surface active sites for photocatalysis performance. HR-TEM images are related to lattice fringes, and SAED patterns of the $\mathrm{TiO}_{2}$ NFs are pictured in Figure S3a. The lattice space $0.351 \mathrm{~nm}$ proves the anatase $\mathrm{TiO}_{2}$ for the (101) plane in the mesoporous $\mathrm{TiO}_{2}$ NFs (inset). The SAED image reveals the diffraction patterns for (101), (004), (200), (105), and (211), which are due to the crystalline anatase $\mathrm{TiO}_{2}$. Figure $\mathrm{S} 3 \mathrm{~b}$ defines the amorphous SAED picture of the mesoporous $\mathrm{SiO}_{2} \mathrm{NFs}$. This is because of the absence of a ring pattern. The SAED pattern (Figure S3c) proves the crystalline nature of the NST NFs and the plane (103) is responsible for N. The lattice spacing of
SNT NFs is $0.345 \mathrm{~nm}$ (Figure S3c, inset). The decrease of the lattice spacing from $0.351 \mathrm{~nm}\left(\mathrm{TiO}_{2} \mathrm{NFs}\right)$ to $0.345 \mathrm{~nm}$ (NST $\mathrm{NFs}$ ) is may be due to the dual incorporation of $\mathrm{N}$ and $\mathrm{S}$ into the $\mathrm{TiO}_{2}$ lattice.

The TEM, STEM, and HR-TEM micrographs of mesoporous FeSiNST NFs are presented in Figure 4. A honeycomb-
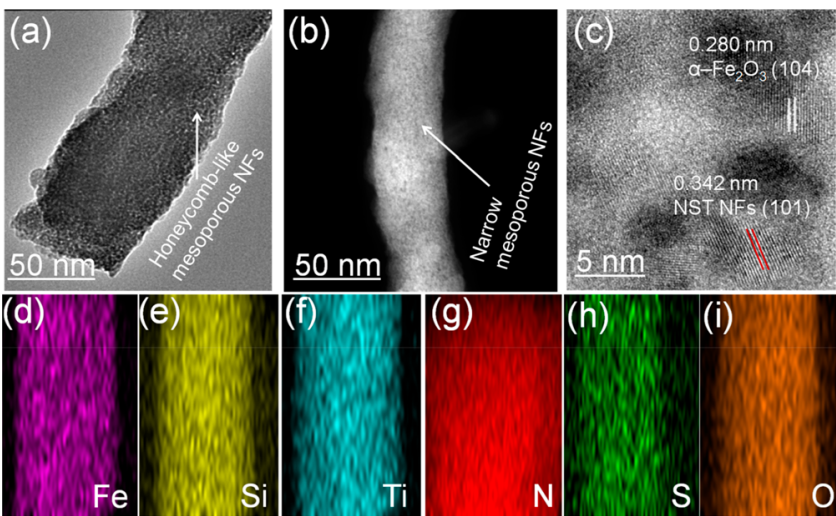

Figure 4. Mesoporous FeSiNST NFs: (a) TEM image, (b) STEM image, (c) lattice fringes (HR-TEM), and (d-i) EDX mapping patterns.

like and narrow mesoporosity within NFs have been identified in TEM and STEM images in Figure 4, parts $a$ and b, respectively, which is consistent with $\mathrm{N}_{2}$ adsorptiondesorption study. From TEM and STEM images, the diameter of the NFs is measured as $84 \pm 3 \mathrm{~nm}$ (Table S1), which is in the nano range. Therefore, the architecture "mesoporosity-inFeSiNST NFs" is created as in $\mathrm{TiO}_{2} \mathrm{NFs}, \mathrm{SiO}_{2}$ NFs, and SNT NFs. The lattice space (Figure 4c) of $0.342 \mathrm{~nm}$ for NST (101), and $0.280 \mathrm{~nm}$ for $\alpha-\mathrm{Fe}_{2} \mathrm{O}_{3}$ (104) are calculated for FeSiNST NFs. ${ }^{27}$ The diminution in lattice spacing in NST NFs within FeSiNST than in neat NST NFs is because of the creation of FeSiNST NFs. The lattice borders represent the polycrystalline nature, which is owing to the existence of $\alpha-\mathrm{Fe}_{2} \mathrm{O}_{3}, \mathrm{SiO}_{2}, \mathrm{~N}, \mathrm{~S}$, and $\mathrm{TiO}_{2}$. The unavailability of $\mathrm{SiO}_{2}$ lattice fringes in FeSiNST NFs (Figure 4c) is due to amorphous nature, which is consistent with XRD measurement (Figure 1c). The polycrystalline nature of FeSiNST NFs is also supportive for harvesting visible light. The dispersal of metal atoms and reactive sites on mesoporous FeSiNST NFs has been confirmed from EDX mapping (Figure $4 \mathrm{~d}-\mathrm{i}$ ). It is observed that $\mathrm{Fe}, \mathrm{Si}, \mathrm{Ti}, \mathrm{N}, \mathrm{S}$, and $\mathrm{O}$ are available in the FeSiNST NFs. STEM-EDX elemental study also supports the presence of individual metal atoms in mesoporous $\mathrm{TiO}_{2} \mathrm{NFs}, \mathrm{SiO}_{2} \mathrm{NFs}$, NST NFs, and FeSiNST NFs in Figure S4a-d.

3.3. Optical Analyses. The UV-vis-NIR diffuse reflectance spectra of all NFs are exposed in Figure 5a. For $\mathrm{TiO}_{2} \mathrm{NFs}$ and $\mathrm{SiO}_{2} \mathrm{NFs}$ samples, the strong reflectance edge which is less than $400 \mathrm{~nm}$ corresponds to anatase $\mathrm{TiO}_{2}$ and amorphous $\mathrm{SiO}_{2}$, respectively. The shifting of band edge, i.e., greater than $400 \mathrm{~nm}$ in the case of NST NFs and FeSiNST NFs, is because of the long-range visible light absorption. The wide visible light absorption is because of the replacement of $\mathrm{N}$ and $\mathrm{S}$ by replacing $\mathrm{O}$ atom in $\mathrm{TiO}_{2}$ lattice (NST NFs). The high shifting of band edge in FeSiNST NFs is owing to the combined effect such as replacement of $\mathrm{N}$ and $\mathrm{S}$ by $\mathrm{O}$ atom in $\mathrm{TiO}_{2}$ lattice and charge transferral phenomena between $\alpha$ $\mathrm{Fe}_{2} \mathrm{O}_{3}$ and $\mathrm{TiO}_{2}$. Apparently, $\alpha-\mathrm{Fe}_{2} \mathrm{O}_{3}, \mathrm{~N}$ and $\mathrm{S}$ dual incorporation, creates a defect level in between the band gap 

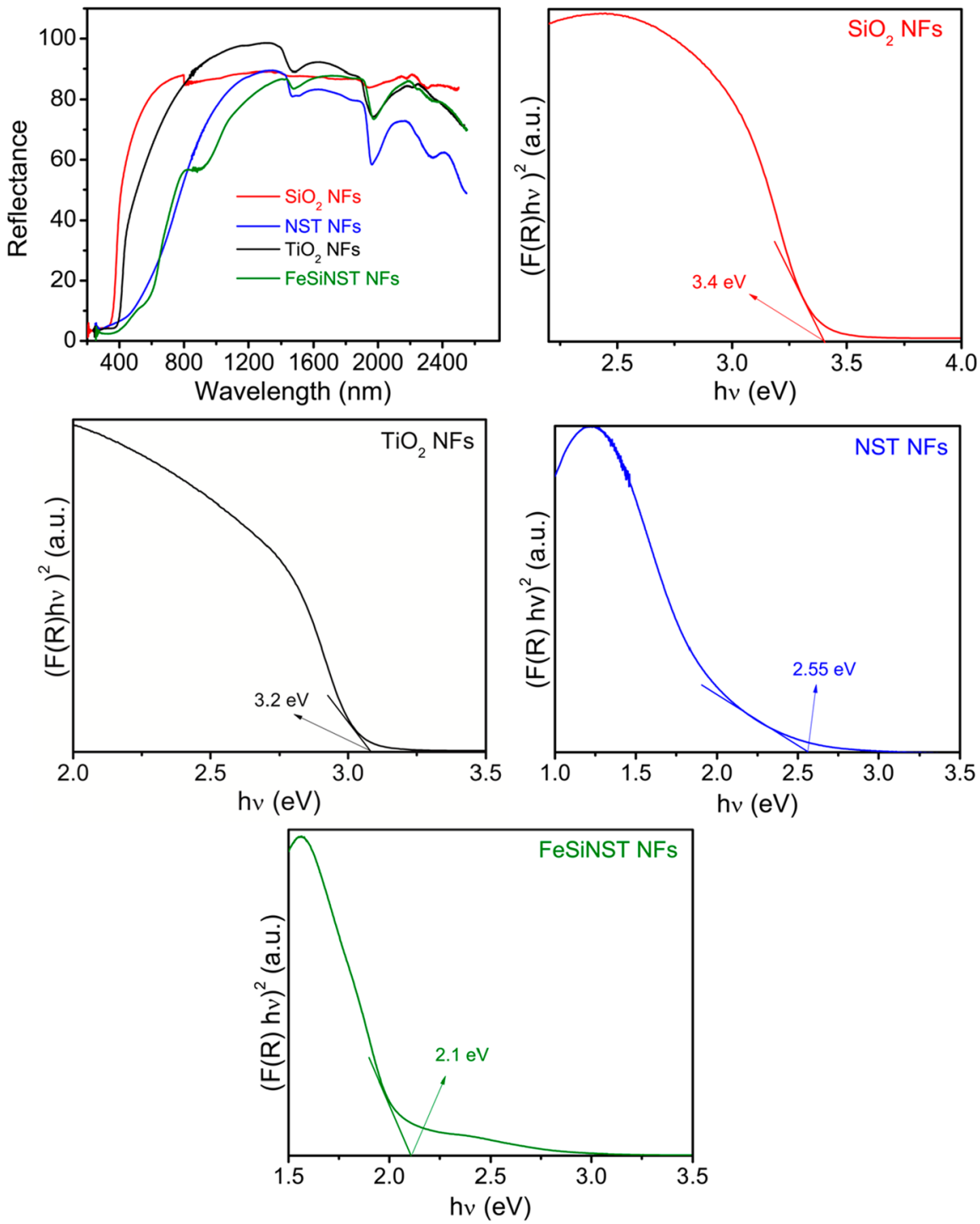

Figure 5. UV-vis-NIR DRS and band gap profiles of mesoporous $\mathrm{SiO}_{2} \mathrm{NFs}, \mathrm{TiO}_{2} \mathrm{NFs}$, NST NFs, and FeSiNST NFs.

of $\mathrm{TiO}_{2}$ and thus the band edge of the FeSiNST NFs shifting toward the visible region. The formation of $\alpha-\mathrm{Fe}_{2} \mathrm{O}_{3}$ in the mesoporous FeSiNST NFs creates a charge transfer and $d-d$ transition phenomenon which is clearly described in the UVvis-NIR diffuse reflectance spectra (Figure S5). The FeSiNST NFs show two transition bands: the first range between 496 and $646 \mathrm{~nm}$ is ascribed to the $3 \mathrm{~d}$ electrons (excitation) of $\mathrm{Fe}^{3+}$ to the conduction band $(\mathrm{CB})$ of $\mathrm{TiO}_{2}$. This phenomenon is called the charge transfer transition. Second, the range between 802 and $1041 \mathrm{~nm}$ is credited to two transitions: one is the d-d transition of $\mathrm{Fe}^{3+}\left({ }^{2} \mathrm{~T}_{2 \mathrm{~g}} \rightarrow{ }^{2} \mathrm{~A}_{2 \mathrm{~g}}\right)$ and the second is the inner charge transfer transition in between $\mathrm{Fe}^{3+}$ through the $\mathrm{CB}$ $\left(\mathrm{Fe}^{3+}+\mathrm{Fe}^{3+} \rightarrow \mathrm{Fe}^{4+}+\mathrm{Fe}^{2+}\right) .{ }^{22}$ This infers that involvement of $\mathrm{Fe}^{3+}$ from $\alpha-\mathrm{Fe}_{2} \mathrm{O}_{3}$ along with $\mathrm{N}$ and $\mathrm{S}$ in the $\mathrm{TiO}_{2}$ lattice brings two electronic states, i.e., $\mathrm{Fe}^{4+}$ and $\mathrm{Fe}^{2+}$, in between the band gap of $\mathrm{TiO}_{2}$. This phenomenon enhances high light absorption and red shifting in the mesoporous FeSiNST NFs than other NFs photocatalysts. Hence, it is concluded that $\mathrm{N}$ and $\mathrm{S}$ dual incorporated $\mathrm{TiO}_{2}$ NFs (NST NFs) favor red shifting due to the substitutional effect, whereas mixing of $\alpha$ $\mathrm{Fe}_{2} \mathrm{O}_{3}$ as catalytic promoter, and dual $\mathrm{N}$ and $\mathrm{S}$ in FeSiNST NFs, favors red shifting. The red shifting is due to the charge transfer transition, $\mathrm{d}-\mathrm{d}$ transition, and substitutional effect. The red shifting phenomenon enables superior visible light photocatalysis application. The combined Kubelka-Munk $[\mathrm{K}-\mathrm{M} / F(R)]$ and Tauc equation is employed to evaluate the band gap energy of the NFs samples. ${ }^{28}$ The detailed explanation is included in the Supporting Information. The band gap energies of all the NFs photocatalysts are given in Figure 5. The band gap of $\mathrm{SiO}_{2} \mathrm{NFs}$ is $3.4 \mathrm{eV}$ (Figure 5), which indicates inactive samples in visible light. The band gap of $3.2 \mathrm{eV}$ is calculated for mesoporous $\mathrm{TiO}_{2} \mathrm{NFs}$, which indicates the anatase phase and UV-responsive material. The band gap of $2.55 \mathrm{eV}$ is calculated for mesoporous NST NFs, which is smaller than that for $\mathrm{TiO}_{2}$ NFs. Hence, the band gap lowering is because of the creation of a localized state by intermixing of $2 \mathrm{p}$ orbitals of $\mathrm{N}, \mathrm{S}$, and $\mathrm{Ti}$. The lowest band gap energy of FeSiNST NFs $(2.1 \mathrm{eV})$ is because of the intermixing of $2 \mathrm{p}$ orbitals of $\mathrm{Fe}, \mathrm{Si}, \mathrm{N}, \mathrm{S}$, and $\mathrm{Ti}$, resulting in a localized state. These localized states are created in between the valence band $(\mathrm{VB})$ and the conduction band ( $\mathrm{CB}$ ) which is lowering the band gap. Moreover, $\alpha-\mathrm{Fe}_{2} \mathrm{O}_{3}$ in FeSiNST NFs has a vital role in decreasing the band gap energy which is because of $d-d$ transition and charge transfer phenomena. 
To evaluate charge transfer phenomena, recombination of $\mathrm{e}^{-}-\mathrm{h}^{+}$, and vacancy in semiconductor NFs, photoluminescence (PL) emission spectra have been pictured. The PL spectra of all NFs materials are generated with an excitation wavelength of $\lambda_{\mathrm{exc}}=390 \mathrm{~nm}$, and the result is pictured in Figure 6a,b. In

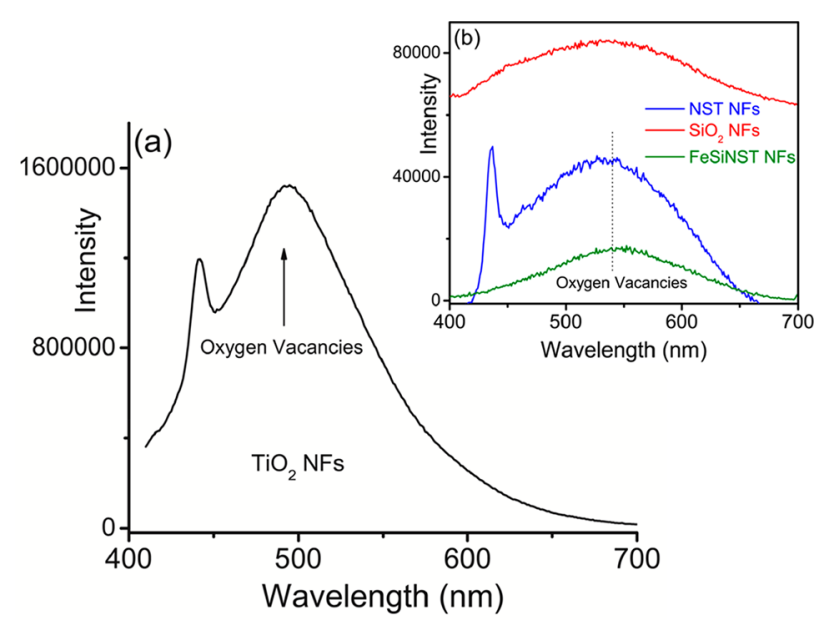

Figure 6. (a) PL spectra of mesoporous $\mathrm{TiO}_{2} \mathrm{NFs}$ and (b) mesoporous $\mathrm{SiO}_{2}$ NFs, NST NFs, and FeSiNST NFs.

Figure 6a, two peaks around 440 and $495 \mathrm{~nm}$ are observed for $\mathrm{TiO}_{2}$ NFs. The emission band situated at $440 \mathrm{~nm}$ is because of the surface trapped recombination. ${ }^{29}$ The peak at $495 \mathrm{~nm}$ (emission) can be consigned to the bulk defects trapped recombination. This peak appears due to the occurrence of impurities in the $\mathrm{TiO}_{2} \mathrm{NFs}^{30}$ The impurities are due to the $\mathrm{O}_{\mathrm{vs}}$ which are created under the $\mathrm{CB}$ of the $\mathrm{TiO}_{2} \mathrm{NFs}^{31}$ The PL spectrum of mesoporous $\mathrm{SiO}_{2}$ NFs (Figure 6b) shows a broad peak around $450-600 \mathrm{~nm}$ which is due to the amorphous nature of the $\mathrm{SiO}_{2}{ }^{32}$ The PL peaks of the semiconductor NST NFs and FeSiNST NFs are lower than those of the $\mathrm{TiO}_{2}$ NFs (Figure 6a,b). It is recognized that the $\mathrm{PL}$ emission depicts the recombination of excited $\mathrm{e}^{-}-\mathrm{h}^{+}$. Thus, decrease in PL intensity confirms a lower recombination rate of $\mathrm{e}^{-}$and $\mathrm{h}^{+} .^{33}$ The least recombination of $\mathrm{e}^{-}-\mathrm{h}^{+}$favors the superior photocatalysis performance. The semiconductor FeSiNST NFs has the least $\mathrm{e}^{-}-\mathrm{h}^{+}$recombination compared with other synthesized NFs. Hence, FeSiNST NFs will act as a proficient photocatalyst for the photoreduction of $\mathrm{Cr}(\mathrm{VI})$, and the photodegradation of 4-NP and phenol. Additionally, the least $\mathrm{e}^{-}-\mathrm{h}^{+}$recombination of FeSiNST NFs is because of the formation of $\mathrm{O}_{\mathrm{vs}}, \mathrm{d}-\mathrm{d}$ transition, and charge transfer transition. ${ }^{34}$ The $\mathrm{O}_{\mathrm{vs}}$ of the NST NFs and FeSiNST NFs are pictured in Figure $6 \mathrm{~b}$. Mesoporous NST NFs and FeSiNST $\mathrm{NFs}$ show $\mathrm{O}_{\mathrm{vs}}$ at $540 \mathrm{~nm}$. The $\mathrm{N}$ and $\mathrm{S}$ dual incorporation into $\mathrm{TiO}_{2}$ (NST NFs) leads to the construction of $\mathrm{Ti}^{3+}$. The photoemission electrons are trapped by $\mathrm{Ti}^{3+}$ from the $\mathrm{CB}$ of $\mathrm{TiO}_{2}$ through nonradiative transition. Further, the $\mathrm{O}_{\mathrm{vs}}$ help to accept the excited electrons, while the $\mathrm{h}^{+}$are trapped by the $\mathrm{N}$ and $\mathrm{S}$. Moreover, the excited electrons can also be transferred from the VB to the new defect level which are introduced by $\mathrm{N}$ and $S$ that are situated below the $\mathrm{CB}$. This process inhibits the recombination of $\mathrm{e}^{-}-\mathrm{h}^{+}$and the resulting swift photoreduction and photodegradation in visible light. Furthermore, a high rate of interfacial charge transfer favors quantum confinement which is because of the enhanced thermodynamic energy of the confined $\mathrm{e}^{-}-\mathrm{h}^{+}$pairs. ${ }^{35}$ The creation of interfacial charges in the FeSiNST NFs is due to the existence of $\mathrm{Fe}^{3+}\left(\mathrm{Fe}^{3+}+\right.$ $\left.\mathrm{Fe}^{3+} \rightarrow \mathrm{Fe}^{4+}+\mathrm{Fe}^{2+}\right)$. Technically, the compensation of electrons within $\mathrm{Fe}$ ions leads to $\mathrm{e}^{-}-\mathrm{h}^{+}$recombination. This phenomenon benefits decreasing the $\mathrm{e}^{-}-\mathrm{h}^{+}$recombination, resulting in lowering the PL intensity over other NFs. In $d-d$ transition phenomena, $\mathrm{Fe}^{3+}$ ions can acquire lattice locations by replacing $\mathrm{Ti}^{4+}$ ions or can be placed in interstitial positions, whereas the $\mathrm{O}_{\mathrm{vs}}$ help to maintain the electrical charge balance. The depletion of peak intensity in the FeSiNST NFs is due to the $\mathrm{O}_{\mathrm{vs}}$ which are involved in charge/electrical balance phenomena. Thus, in FeSiNST NFs, the formation of interfacial charge transfers and $\mathrm{d}-\mathrm{d}$ transitions has a vital role in decreasing PL intensity and suppressing $\mathrm{e}^{-}-\mathrm{h}^{+}$ recombination. Conclusively, $\mathrm{N}$ and $\mathrm{S}$ dual incorporated $\mathrm{TiO}_{2}$ generates $\mathrm{O}_{v s}$, whereas involvements of $\alpha-\mathrm{Fe}_{2} \mathrm{O}_{3}$ (FeSiNST NFs) generate charge transfer transition and $\mathrm{d}-\mathrm{d}$ transition. This process really helps to lower $\mathrm{e}^{-}-\mathrm{h}^{+}$ recombination and enhance photocatalysis activity.

3.4. Chemical Structure Analyses. The XPS study of mesoporous FeSiNST NFs is performed in Figure 7. In
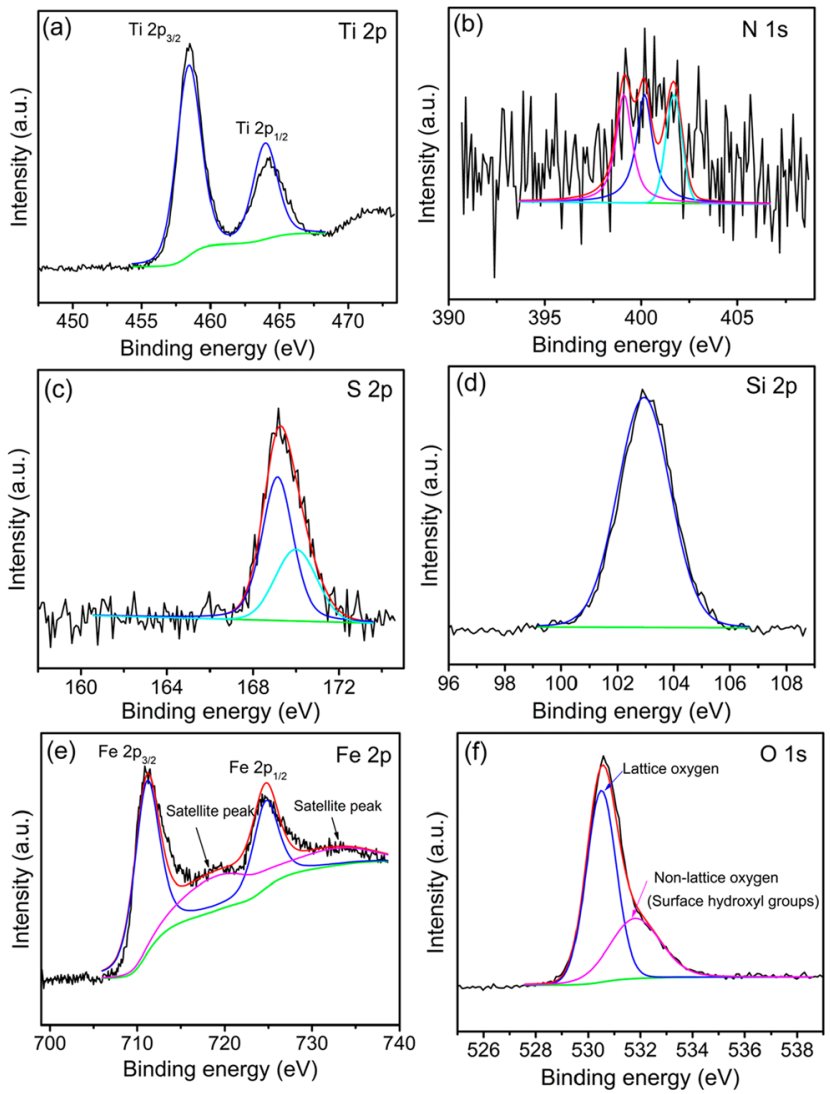

Figure 7. Core level spectra of Ti $2 p(a), N$ 1s (b), S $2 p(c), S i 2 p$ (d), Fe 2p (e), and O 1s (f) in mesoporous FeSiNST NFs.

FeSiNST NFs, the binding energy $(\mathrm{BE})$ values are situated at 458.4 and $464.1 \mathrm{eV}$ for the peaks $\mathrm{Ti} 2 \mathrm{p}_{3 / 2}$ and $\mathrm{Ti} 2 \mathrm{p}_{1 / 2}$, respectively (Figure $7 \mathrm{a}$ ). But the $\mathrm{BE}$ values of $\mathrm{Ti}^{4+}$ in neat $\mathrm{TiO}_{2}$ are also calculated, which appear around 459.3 and $464.8 \mathrm{eV}$ (Figure S6) for the peaks Ti $2 \mathrm{p}_{3 / 2}$ and Ti $2 \mathrm{p}_{1 / 2}$, respectively. ${ }^{36}$ The downshift of $\mathrm{Ti}^{4+} \mathrm{BE}$ in FeSiNST NFs compared with neat $\mathrm{TiO}_{2}$ indicates the simultaneous electron transfer from $\mathrm{N}$ and $\mathrm{S}$ to $\mathrm{Ti}$ (forming $\mathrm{Ti}^{3+}$ environment). Another situation is electron transfer from $\mathrm{O}$ atom $\left(\alpha-\mathrm{Fe}_{2} \mathrm{O}_{3}\right.$ and $\left.\mathrm{SiO}_{2}\right)$ to Ti. This 
is because of the electronegative and electropositive differences between $\mathrm{O}$ and $\mathrm{Ti}$, respectively. The aforesaid factors are the vibrant reason for the reduction of $\mathrm{Ti}^{4+}$ to $\mathrm{Ti}^{3+}$ in the FeSiNST NFs which enable visible light shifting. The peak at 399 and $400 \mathrm{eV}$ (Figure $7 \mathrm{~b}$ ) is due to the presence of $\mathrm{N}$ in the bonding type of $\mathrm{O}-\mathrm{Ti}-\mathrm{N}$ and $\mathrm{Ti}-\mathrm{N}-\mathrm{O}$ through substitutional and interfacial combinations, respectively. This $\mathrm{N}$ incorporation formed the $\mathrm{N} 2 \mathrm{p}$ localized state in between the VB and the $\mathrm{CB}$ of $\mathrm{TiO}_{2}$, resulting in visible light absorption. This process enables an efficient photocatalysis performance under visible light. The $\mathrm{N} \mathrm{1s} \mathrm{peak} \mathrm{around} \mathrm{at} 401.6 \mathrm{eV}$ is ascribed to the existence of $\mathrm{N}$ in oxidized state, which may form $-\mathrm{Ti}-\mathrm{N}-\mathrm{O}-$, $-\mathrm{Ti}-\mathrm{O}-\mathrm{N}-$ linkage. This oxidized $\mathrm{N}$ forms a close interaction toward $\mathrm{O}$, which is favorable for an interstitial $\mathrm{N}$ incorporation. ${ }^{37}$ Hence, the bonding framework of $-\mathrm{Fe}-\mathrm{O}-$ $\mathrm{N}-$ and $-\mathrm{Si}-\mathrm{O}-\mathrm{N}-$ may be likely in FeSiNST NFs. The keen observation is that, in the FeSiNST NFs, the substitution of $\mathrm{N}$ by $\mathrm{O}$ is a vital aspect because of the presence of $\mathrm{TiO}_{2}, \alpha$ $\mathrm{Fe}_{2} \mathrm{O}_{3}$, and $\mathrm{SiO}_{2}$. In the $\mathrm{S} 2 \mathrm{p}$ spectrum (Figure $7 \mathrm{c}$ ) two peaks appear at 169.1 and $170 \mathrm{eV}$, conforming to $S^{6+38}$. Hence, $S$ atom is incorporated into the FeSiNST mainly as $S^{6+}$. It has been observed that replacement of $\mathrm{Ti}^{4+}$ by $\mathrm{S}^{6+}$ is more facile and suitable, when thiourea is used as the sulfur source. ${ }^{39}$ It has been examined that the substitution of $\mathrm{Ti}^{4+}$ by $\mathrm{S}^{6+}$ generates $\mathrm{O}_{\mathrm{vs}}$ in the $\mathrm{TiO}_{2}$ lattice. ${ }^{40}$ Thus, in the present study, $\mathrm{S}$ is incorporated into the FeSiNST NFs in the form of substitution of $\mathrm{Ti}^{4+}$ by $\mathrm{S}^{6+}$, which creates $\mathrm{O}_{\mathrm{vs}}$. Hence, the generation of $\mathrm{O}_{\mathrm{vs}}$ is also proved by XPS analysis. It is noted that the BE of Si $2 p$ in neat $\mathrm{SiO}_{2}$ is $103.7 \mathrm{eV} .^{41}$ But in the present study the $\mathrm{BE}$ of Si $2 \mathrm{p}\left(\mathrm{Si}^{4+}\right)$ in the FeSiNST NFs is $102.9 \mathrm{eV}$ (Figure $7 \mathrm{~d}$ ). The downshift of $\mathrm{BE}$ is owing to the transfer of electrons from $\mathrm{N}$ to $\mathrm{Si}^{4+}$ which causes an increase of electron density over $\mathrm{Si}^{4+}$. It is also well-known that the two characteristic BEs at $712.1 \mathrm{eV}$ (Fe $\left.2 \mathrm{p}_{3 / 2}\right)$ and $725.5 \mathrm{eV}\left(\mathrm{Fe} 2 \mathrm{p}_{1 / 2}\right)$ and a satellite peak at $719.1 \mathrm{eV}$ are because of the $\alpha-\mathrm{Fe}_{2} \mathrm{O}_{3}$. ${ }^{42}$ In the present investigation, the peaks are at 711.1 and $724.8 \mathrm{eV}$ analogous to the $\mathrm{Fe} 2 \mathrm{p}_{3 / 2}$ and Fe $2 \mathrm{p}_{1 / 2}$, respectively, along with the two satellite peaks are at nearly 719 and $724.8 \mathrm{eV}$, proving the existence of $\alpha-\mathrm{Fe}_{2} \mathrm{O}_{3}$ in the FeSiNST NFs (Figure 7e). The low BE shifting of Fe $2 \mathrm{p}$ in FeSiNST NFs compared with pure Fe $2 p$ is because of the electron transfer from $\mathrm{Ti}^{4+}$ to $\mathrm{Fe}^{3+}$ and the generated -Ti-O$\mathrm{Fe}-$ bonding framework. The electron transfer from $\mathrm{Ti}^{4+}$ to $\mathrm{Fe}^{3+}$ is due to the electronegativity differential between $\mathrm{Fe}^{3+}$ (1.83) and $\mathrm{Ti}^{4+}(1.54)$. Hence, the electron density of $\mathrm{Ti}^{4+}$ ion is lower than that of $\mathrm{Fe}^{3+}$. This phenomenon enables the rise of the $\mathrm{BE}$ of $\mathrm{Ti}^{4+}$ and the fall of the $\mathrm{BE}$ of $\mathrm{Fe}^{3+}$. The $\mathrm{BE}$ of $\mathrm{O} 1 \mathrm{~s}$ (Figure 7f) in FeSiNST NFs is located at $530.5 \mathrm{eV}$, owing to the lattice oxygen, suggesting the existence of $\mathrm{Ti}-\mathrm{O}$ bonding in $\mathrm{TiO}_{2}{ }^{43}$ The peak at ca. $531.8 \mathrm{eV}$ (nonlattice oxygen) is because of the surface hydroxyl available in the FeSiNST NFs. Additionally, the peak at $531.8 \mathrm{eV}$ is also ascribed to the presence of $-\mathrm{S}-\mathrm{O}-\mathrm{S}-$ linkage. ${ }^{38}$ It has been also observed that the rise in the area of nonlattice oxygen specifies the creation of $\mathrm{O}_{\mathrm{vs}}{ }^{44}$ In Figure $7 \mathrm{f}$, the peak area of the nonlattice oxygen is nearly half that of the lattice oxygen, which also proves the generation of the $\mathrm{O}_{\mathrm{vs}}$ in $\mathrm{TiO}_{2}$ lattice (FeSiNST NFs).

3.5. Electrochemical Performance. The photoelectrochemical study of mesoporous FeSiNST NFs along with NST NFs has been studied (Figure 8). In order to measure the photocurrent, charge density, and rate of charge transfer at the electrode/electrolyte interface within NFs, the photocurrent measurement, MS (Mott-Schottky) diagram, and EIS (electrochemical impedance spectroscopy) are studied, respectively. The photocurrent of mesoporous NST NFs and FeSiNST NFs is measured in $0.1 \mathrm{M} \mathrm{Na}_{2} \mathrm{SO}_{4}(0.1 \mathrm{M})$ at $10 \mathrm{mV}$ $\mathrm{s}^{-1}$ scan rate in $\lambda \geq 400 \mathrm{~nm}$. The photocurrent densities, i.e., 1.8 and $3.2 \mathrm{~mA} / \mathrm{cm}^{2}$, are calculated for mesoporous NST NFs and FeSiNST NFs, respectively (Figure 8a). The photocurrents in both NFs with positive values represent the anodic direction with the applied potential, resulting n-type semiconductors. The mesoporosity within NFs has a key role in a proficient harvest of photocurrent in both NFs. The harvesting of higher photocurrent in FeSiNST NFs than in NST NFs is owing to the efficient charge transport within NFs. ${ }^{45}$ The superior charge transport in FeSiNST NFs is because of $\alpha$ $\mathrm{Fe}_{2} \mathrm{O}_{3}$. This efficient charge transport is because of the $d-d$ transition and charge transfer transition, which leads to enhancement of the electron mobility or electron density. The high electron mobility over FeSiNST NFs increases the photocatalysis performance.

The MS method has been used to check the band arrangement and recombination properties. This process is calculated in three-electrode systems using the counter electrode $(\mathrm{Pt})$ and reference electrode $(\mathrm{Ag} / \mathrm{AgCl})$, and both are dipped in $\mathrm{Na}_{2} \mathrm{SO}_{4}(0.1 \mathrm{M})$ in $1000 \mathrm{~Hz}$ at $\mathrm{pH} 6.5$ in the dark. Figure $8 b-d$ represents the MS diagram of $\alpha-\mathrm{Fe}_{2} \mathrm{O}_{3} \mathrm{NFs}$, NST NFs, and FeSiNST NFs. The SEM image and the EDX elemental analysis of $\alpha-\mathrm{Fe}_{2} \mathrm{O}_{3} \mathrm{NFs}$ has been inserted in Figure S7. The positive slope for all samples shows n-type semiconductor behavior. The mesoporous FeSiNST NFs having a single slope specifies that $\alpha-\mathrm{Fe}_{2} \mathrm{O}_{3}$ is crucially promoted in the photocatalysis activity with $\mathrm{N}$ and $\mathrm{S}$ dual incorporated $\mathrm{TiO}_{2}$. Moreover, from the intercept of the MS diagram (Figure $8 \mathrm{~b}-\mathrm{d}$ ), the $E_{\mathrm{fb}}$ (flat band potentials) for $\alpha$ $\mathrm{Fe}_{2} \mathrm{O}_{3}$ NFs, NST NFs, and FeSiNST NFs are calculated as $-0.61,-0.78$, and $-1.0 \mathrm{~V}$, respectively. A higher magnitude of negative value for the $E_{\mathrm{fb}}$ in semiconductor (n-type) specifies enhanced transport and separation of charge carriers at the interface of electrolyte-electrode, resulting in enriched photoelectrochemical performance. ${ }^{46}$ The FeSiNST NFs have a more negative $E_{\mathrm{fb}}$ than NST NFs and $\alpha-\mathrm{Fe}_{2} \mathrm{O}_{3}$ NFs. Thus, separation and transport of charge carriers is better facilitated in FeSiNST NFs, which thereby exhibit a better photoelectrochemical response. This process makes the photocatalysis applications excel. It is understood that mixing of metal ions with increased valence states such as $\mathrm{Ti}^{4+}$ and $\mathrm{Si}^{4+}$ results in enhanced electron density on $\alpha-\mathrm{Fe}_{2} \mathrm{O}_{3}$, by acting as donor. ${ }^{47}$ The low impedance for the FeSiNST NFs is because of the high charge density is directly related to the conductance, which is calculated by the formula $\sigma=n e_{0} \mu$. The better conductivity (electrical) may spread the lifespan of charge carriers, which helps to decrease the $\mathrm{e}^{-}-\mathrm{h}^{+}$ recombination. ${ }^{48}$ Thus, the enhanced charge density and lower $\mathrm{e}^{-}-\mathrm{h}^{+}$recombination in the surface by the mixing of $\mathrm{Ti}$ and $\mathrm{Si}$ surface is supposed to be the key aspect for the remarkable photocurrent enhancement of the $\alpha-\mathrm{Fe}_{2} \mathrm{O}_{3}$ in the FeSiNST NFs. The CB potential for n-type semiconductors is nearly equal to $E_{\mathrm{fb}}$. Hence, the locations of the CB for $\alpha-\mathrm{Fe}_{2} \mathrm{O}_{3}$ NFs and NST NFs are -0.61 and $-0.78 \mathrm{~V}$, respectively. Thus, band structure has significant role in the high photocatalysis performance, which is reflected in the photocatalysis section.

The semicircles at higher frequency and the nearly straight line at the lower frequency level (Nyquist plots) are observed in the EIS of mesoporous NST NFs and FeSiNST NFs (Figure $8 \mathrm{e})$. The low frequencies (semicircle) represent the charge 

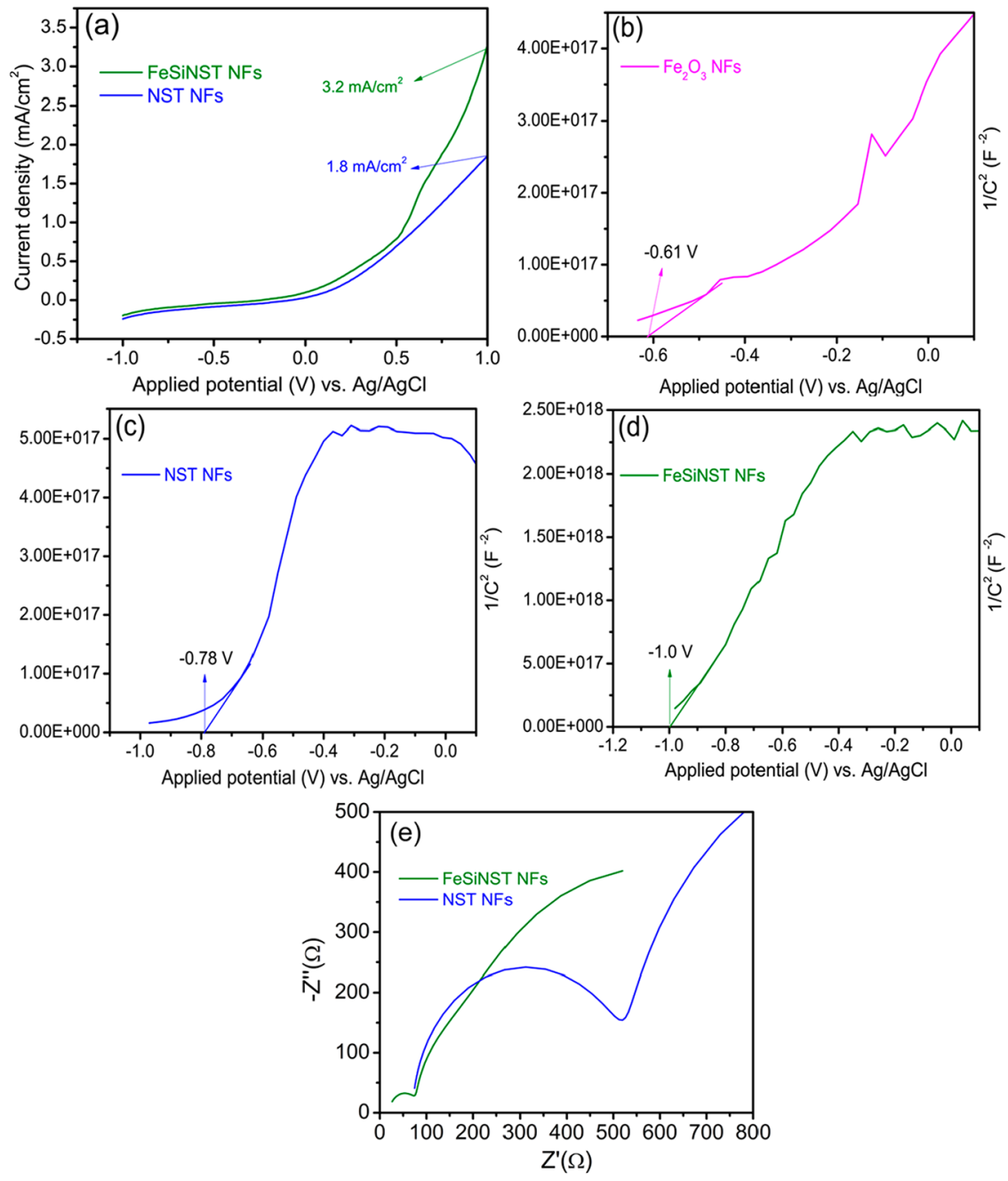

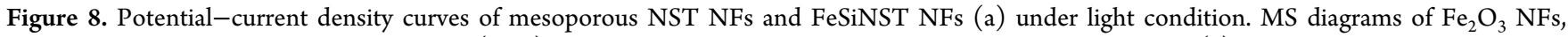
mesoporous NST NFs, and FeSiNST NFs $(b-d)$ in the dark. Nyquist plot for NST NFs and FeSiNST NFs (e).

transfer within the electrode/electrolyte interface, whereas the charge transfer resistance $\left(R_{\mathrm{ct}}\right)$ is calculated from the semicircle diameter. ${ }^{49}$ In the present investigation, the $R_{\text {ct }}$ value for mesoporous NST NFs $(\sim 516 \Omega)$ is greater than that for the FeSiNST NFs $(\sim 74 \Omega)$. It is noted that the bigger semicircle diameter provides the high resistance at the interface, which shows less conductance. The lower $R_{\mathrm{ct}}$ of the FeSiNST NFs is due to the modification of the $\alpha-\mathrm{Fe}_{2} \mathrm{O}_{3}$ which facilitates the facile charge momentum within the interface, thus increasing generation of photocurrent. The lesser $R_{\mathrm{ct}}$ value indicates the greater charge transfer performance in mesoporous FeSiNST NFs. Charge transfer phenomena may progress capably from $\mathrm{TiO}_{2}\left(\mathrm{Ti}^{4+}\right) / \mathrm{SiO}_{2}\left(\mathrm{Si}^{4+}\right)$ to $\alpha-\mathrm{Fe}_{2} \mathrm{O}_{3}\left(\mathrm{Fe}^{3+}\right)$. The charge transfer toward $\alpha-\mathrm{Fe}_{2} \mathrm{O}_{3}\left(\mathrm{Fe}^{3+}\right)$ is because of internal charge transfer transition and $\mathrm{d}-\mathrm{d}$ transition (Figure S5) which creates vacant sites within $\alpha-\mathrm{Fe}_{2} \mathrm{O}_{3}$. Thus, $\alpha-\mathrm{Fe}_{2} \mathrm{O}_{3}$ becomes the charge trap center in FeSiNST NFs. Henceforth, the FeSiNST NFs have a more effective $\mathrm{e}^{-}-\mathrm{h}^{+}$separation than SNT NFs. Thus, FeSiNST NFs will have superior photocatalysis activity which is due to the low $R_{\mathrm{ct}}$ value. Furthermore, in the lower frequency region, a straight line is observed which is due to the $W_{\mathrm{S}}$ (Warburg impedance). This $W_{\mathrm{S}}$ is responsible for the diffusion or transfer of ions within an electrolyte. ${ }^{50}$ The FeSiNST NFs have a lower Warburg region than NST NFs (Figure 8e). The smaller Warburg region of the mesoporous FeSiNST NFs is due to the effective ion movement in the NFs via mesopores and supports superior photocatalysis performance. Hence, enriched current density, charge transfer, and ion momentum in the FeSiNST NFs are the key factors for the improved photocatalysis performance which is because of the mixing of $\alpha-\mathrm{Fe}_{2} \mathrm{O}_{3}$ as electron trap center and mesoporosity within NFs.

3.6. Growth Mechanism. The growth mechanism of mesoporous FeSiNST NFs is described in the origin of the synthesis procedure (Scheme 2). The mesoporous FeSiNST NFs are synthesized on the basis of the electrospinning via sol-gel method. Scheme 2 a depicts the chemical interaction, whereas Scheme $2 \mathrm{~b}$ describes the schematic approach regarding formation of the mesoporous FeSiNST NFs. The precursors of $\mathrm{Ti}, \mathrm{Fe}$, and $\mathrm{Si}$ are diluted in the mixed solvents isopropanol and $\mathrm{H}_{2} \mathrm{O}$ including PVP and CTAB in acetic acid, and then the hydrolysis process is progressed and forms $\mathrm{Ti}(\mathrm{OH})_{4}, \mathrm{Si}(\mathrm{OH})_{4}$, and $\mathrm{Fe}(\mathrm{OH})_{3}$ in the reaction media. These hydroxyl groups make hydrogen bonding with oxygen available in PVP, and also form a hydrogen bond with $\mathrm{N}^{+}$from CTAB. Another possibility is that oxygen atom from metal hydroxide also creates a Coulombic interaction with $\mathrm{N}^{+}$, present in CTAB. The thiourea was also hydrolyzed and the $\mathrm{N}$ and $\mathrm{S}$ 
Scheme 2. Chemical Interaction (a) and Schematic Pathways (b) of Growth Mechanism of Mesoporous FeSiNST NFs

(a)

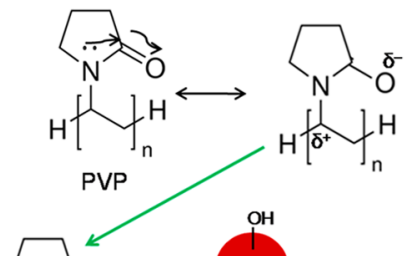
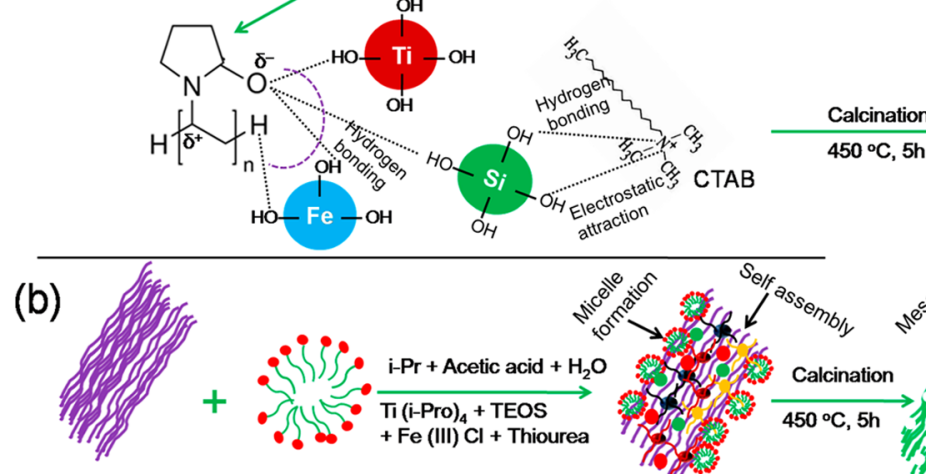

PVP chain
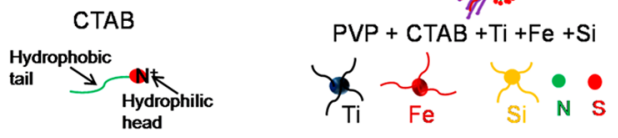

Mesoporous FeSiNST NFs

atoms anchor to the metal hydroxides through oxygen and hydrogen. The nucleation of metal particles and formation of sol are created in this process. The PVP and CTAB formed a polymeric chain and micelles with metal hydroxide sol and finally formed a gel for electrospinning, respectively. The mesoporous FeSiNST NFs are formed after drying $\left(70^{\circ} \mathrm{C}, 3\right.$ h) and calcinations $\left(450{ }^{\circ} \mathrm{C}, 5 \mathrm{~h}\right)$ of PVP and CTAB mixed FeSiNST NFs.

PVP, CTAB, and acetic acid have vital roles for the fabrication of the mesoporous FeSiNST NFs (Scheme 2b). PVP (template) has a long polymeric chain which is responsible for the fabrication of NFs framework during the electrospinning process. Additionally, long chain PVP creates hydrogen bonding with $-\mathrm{OH}$ groups of metals such as $\mathrm{Ti}, \mathrm{Fe}$. and $\mathrm{Si}$. CTAB is an amphiphilic molecule, which contains a hydrophilic head and a hydrophobic tail. It will form the micelles and subsequent nucleation for the growth of metal ( $\mathrm{Ti}, \mathrm{Fe}$, and $\mathrm{Si}$ ) hydroxides. Moreover, after addition of $\mathrm{CTAB}$, the ion pairs are formed due to electrostatic interaction of the active species $\left(\mathrm{N}^{+} \ldots \mathrm{O}^{2-}\right)$, which speed up the reaction of the growth units. During the evaporation of solvent, the selfassembly of CTAB micelles with metal hydroxides occurred, which led to a complete polymerization of the inorganic network. In the crystallization process, the CTAB serves as a pore growth controller and surfactant. During the calcinations, the CTAB decomposes and organic species are removed, leading to formation of the mesoporous FeSiNST NFs. It is stated that the species which are causing foam during hydrolysis help to produce mesoporosity. ${ }^{51}$ The foams are generated after mixing of $C T A B$ in water which leads to formation of a micelle, and resulting mesoporosity within FeSiNST NFs after calcination. The acetic acid in the reaction stabilized the sol. This is because acetic acid has tendency to slow down the condensation and reduce the gelation rate of sol. ${ }^{52}$ The optimum amount of the acetic acid in the reaction solution aids to form perfect NFs. Hence, PVP, CTAB, and acetic acid have vital involvement for the synthesis of mesoporous FeSiNST NFs.
3.7. Photocatalysis Activity of Mesoporous Nanofibers. Photoreduction of $\mathrm{Cr}(\mathrm{VI})$ proceeded under visible light. It is examined that mesoporous FeSiNST NFs have superior $\mathrm{Cr}(\mathrm{VI})$ photoreduction performance. The experiment was continued for $80 \mathrm{~min}$ in visible light, $\mathrm{K}_{2} \mathrm{Cr}_{2} \mathrm{O}_{7}\left(40 \mathrm{mg} \cdot \mathrm{L}^{-1}\right)$ solution, and catalyst dose $\left(1 \mathrm{mg} \cdot \mathrm{mL}^{-1}\right)$. In order to check the effect of $\mathrm{pH}$, the photoreduction of $\mathrm{Cr}(\mathrm{VI})$ progressed on different $\mathrm{pHs}$ (Figure S8). The photoreduction of $\mathrm{Cr}(\mathrm{VI})$ by FeSiNST NFs falls at higher $\mathrm{pH}$. This is because the photocatalyst surface (low $\mathrm{pH}$ ) gets protonated, resulting in formation of $\mathrm{HCrO}_{4}^{-}$species and enhancing the photoreduction process. The photocatalyst surface becomes negative at high $\mathrm{pH}$, which repels the negative species $\mathrm{Cr}_{2} \mathrm{O}_{7}{ }^{2-}$, resulting in low photoreduction activity. The results shows that the highest photoreduction $\mathrm{Cr}(\mathrm{VI})$ is at $\mathrm{pH} 4$. Hence, $\mathrm{pH} 4$ is the optimum $\mathrm{pH}$ condition for the photoreduction of $\mathrm{Cr}(\mathrm{VI})$ by different NFs photocatalysts (Figure 9a). After reaction, the $\mathrm{UV}$-visible absorbance intensity of $\mathrm{Cr}(\mathrm{VI})$ diminishes slowly from $\mathrm{SiO}_{2}$ NFs to FeSiNST NFs. The least absorbance (Figure 9a) in the case of mesoporous FeSiNST NFs specifies proficient photoreduction of $\mathrm{Cr}(\mathrm{VI})$.

The photodegradation of 4-NP and phenol progressed under visible light. The reaction is performed in $100 \mathrm{~min}, 30$ $\mathrm{mg} \cdot \mathrm{L}^{-1}$ (4-NP and phenol), and catalyst dose $\left(1 \mathrm{mg} \cdot \mathrm{mL}^{-1}\right)$. The effect of $\mathrm{pH}$ on the photodegradation of phenol is described in Figure S9. The reactions progressed at different $\mathrm{pH}$ by mesoporous FeSiNST NFs. The photodegradation of phenol was maximum at $\mathrm{pH} 6(100 \%)$, and with a gradual rise of $\mathrm{pH}$ from 6 to 10, the percent of photodegradation decreases. This may be described by the acid strength $\left(\mathrm{p} K_{\mathrm{a}}\right)$ of phenol, i.e., 9.8. Generally phenol dissociation starts at $\mathrm{pH}>\mathrm{pK}$, so at $\mathrm{pH}$ above 9.8, the photodegradation decreases because of phenol ionization, resulting in less photodegradation. The highest photodegradation is observed at $\mathrm{pH}$ 6, which is due to the presence of undissociated phenol. Not only phenol but also the photodegradation percent of 4-NP is seen at $\mathrm{pH}$ 6. The reason is similar to that for phenol photodegradation.

The photodegradation of 4-NP and phenol by different NFs photocatalysts is presented in Figure 9, parts b and c, 

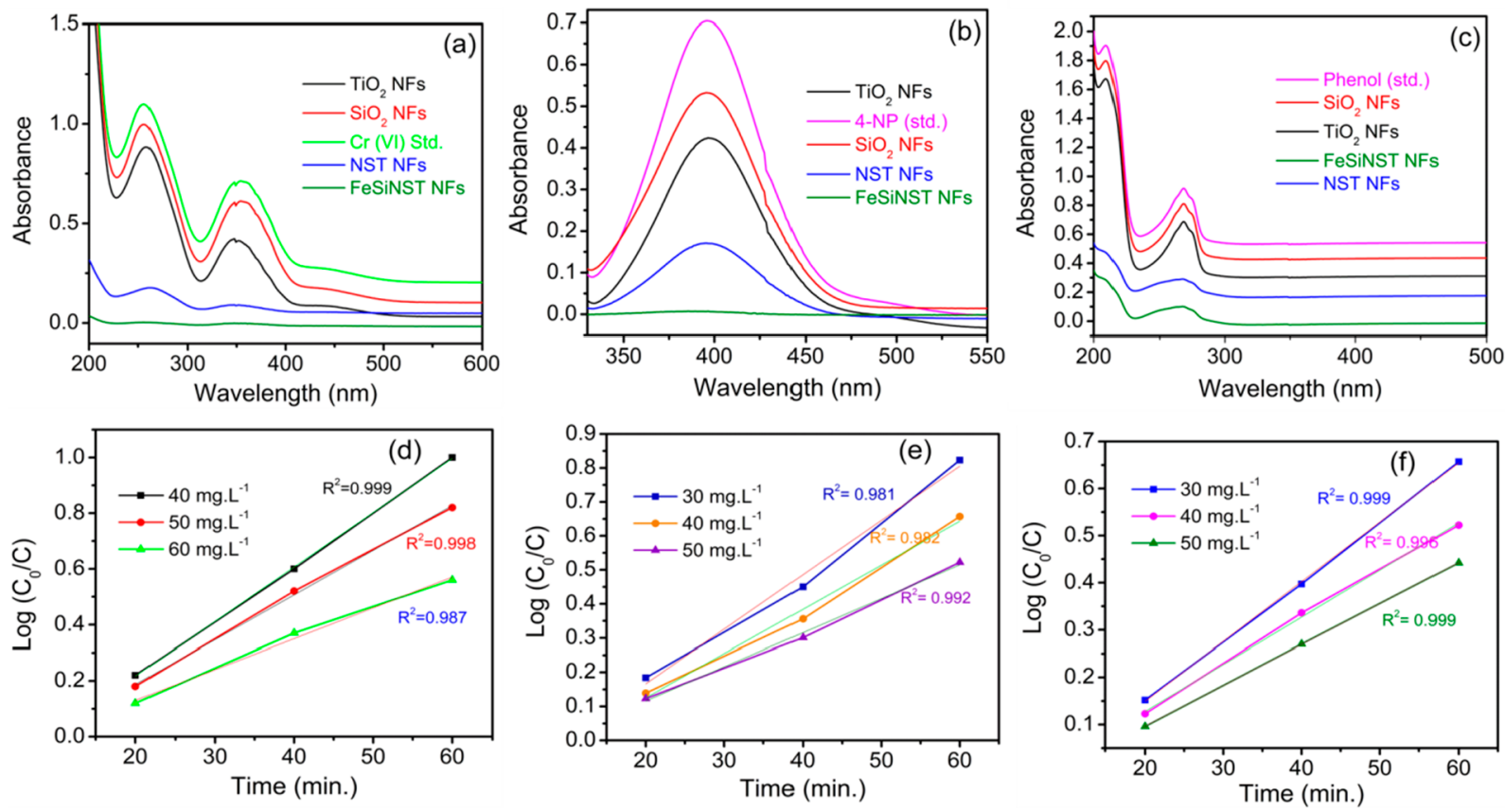

Figure 9. UV-vis spectra of solutions recorded after photoreduction $\mathrm{Cr}(\mathrm{VI})$ (a), and photodegradation of 4-NP (b) and phenol (c) by different photocatalysts $(10 \mathrm{mg}$ in $10 \mathrm{~mL}$ solution) under visible light. The photoreduction process is continued at $\mathrm{pH} 4$ in $80 \mathrm{~min}$, whereas the photodegradation process is at $\mathrm{pH} 6 \mathrm{in} 100 \mathrm{~min}$. The kinetic study is also performed by taking different concentrations $\left(40,50\right.$, and $\left.60 \mathrm{mg} \cdot \mathrm{L}^{-1}\right)$ for $\mathrm{Cr}(\mathrm{VI})(\mathrm{d})$. Concentration varies $\left(30,40\right.$, and $\left.50 \mathrm{mg} \cdot \mathrm{L}^{-1}\right)$ for 4-NP (e) and phenol (f), with different time intervals $(20$, 40, and $60 \mathrm{~min})$ on mesoporous FeSiNST NFs.

respectively. The experiment is performed in $100 \mathrm{~min}$ at $\mathrm{pH} 6$ under visible light. The UV-visible absorbance intensity of 4NP drops from $\mathrm{SiO}_{2}$ NFs to FeSiNST NFs with respect to 4NP (standard). The lowest absorbance in the case of FeSiNST NFs indicates efficient photodegradation of 4-NP (Figure 9b). The photodegradation of phenol by different NFs photocatalysts also followed the same trend as 4-NP, i.e., $\mathrm{SiO}_{2} \mathrm{NFs}<$ $\mathrm{TiO}_{2}$ NFs $<$ NST NFs $<$ FeSiNST NFs. The percent of $\mathrm{Cr}(\mathrm{VI})$ photoreduction, and 4-NP and phenol photodegradation, varies with different photocatalysts as displayed in Table S2. The high percent of $\mathrm{Cr}(\mathrm{VI})$ photoreduction and 4-NP photodegradation as compared to phenol is detected. This is because of the light yellow color of both $\mathrm{Cr}(\mathrm{VI})$ and 4-NP which enables them to absorb visible light proficiently as related to phenol. The increase in photocatalysis (photoreduction and photodegradation) reaction of $\mathrm{Cr}(\mathrm{VI})$, and 4NP and phenol, by mesoporous FeSiNST NFs is because of the mesoporosity within NFs, high light absorption property, charge transfer transition, $\mathrm{d}-\mathrm{d}$ transition, $\mathrm{O}_{\mathrm{vs}}$, and $\mathrm{e}^{-}-\mathrm{h}^{+}$ separation. The high light absorption property is due to the optimum amount of $\mathrm{Ti}, \mathrm{N}$, and $\mathrm{S}$, whereas the optimum amount of $\mathrm{Fe}$ enhances the charge transfer transition and $\mathrm{d}-\mathrm{d}$ transition in FeSiNST NFs. The suitable amount of Si aids in increasing the surface properties for an efficient photoreduction and photodegradation performance.

The mesoporosity within NFs increases the $S_{\mathrm{A}}$, and the high $S_{\mathrm{A}}$ provides fruitful reactive sites for the photocatalysis performance. The mesoporous FeSiNST NFs has a wider $S_{A}$, i.e., $300 \mathrm{~m}^{2} / \mathrm{g}$, than other synthesized NFs; hence the interaction of reactant species with photocatalyst surface will be more, resulting in high photocatalysis performance. The mesoporous $\mathrm{SiO}_{2} \mathrm{NFs}$ have lower photocatalysis activity despite a high $S_{\mathrm{A}}\left(500 \mathrm{~m}^{2} / \mathrm{g}\right)$. This is because of the absence of $\mathrm{N}$ and $\mathrm{S}$ as visible light absorber and $\alpha-\mathrm{Fe}_{2} \mathrm{O}_{3}$ as catalysis promoter. The enhanced light absorption/red shifting is due to the availability of $\mathrm{N}$ and $\mathrm{S}$ as visible light absorber in photocatalyst NST NFs and FeSiNST NFs (UV-vis-NIR DRS spectra). But mesoporous FeSiNST NFs have a higher photocatalysis performance than mesoporous NST NFs. Hence, it is understood that $\alpha-\mathrm{Fe}_{2} \mathrm{O}_{3}$ has a tremendous role which makes FeSiNST NFs a superior photocatalysis. The $d-d$ transition and charge transfer transition are created owing to the presence of $\mathrm{Fe}^{3+}\left(\alpha-\mathrm{Fe}_{2} \mathrm{O}_{3}\right)$ in FeSiNST NFs (UV-visNIR DRS spectra). According to crystal field theory, it is known that $\mathrm{Fe}_{2} \mathrm{O}_{3}$ has vacant $\mathrm{d}$ orbitals. Hence, $\mathrm{Fe}^{3+}$ in composite FeSiNST NFs can capture electrons through $d-d$ transition, resulting in lowering $\mathrm{e}^{-}-\mathrm{h}^{+}$and enhancing photocatalysis activity. But the charge transfer transition induces $\mathrm{Fe}^{4+}$ and $\mathrm{Fe}^{2+}$ electronic states within $\mathrm{N}$ and $\mathrm{S}$ in the $\mathrm{TiO}_{2}$ lattice, resulting in an impurity state and decreasing the band gap. This phenomenon enhances the light absorption in visible light. Furthermore, the formation of interfacial charge in the composite FeSiNST NFs is due to the presence of $\mathrm{Fe}^{3+}$, which enhances the light absorption property and suppresses the charge recombination. The $\mathrm{d}-\mathrm{d}$ transition and charge transfer transition phenomenon also enhances the light absorption property and red shift, resulting in high photocatalysis performance in FeSiNST NFs. Although NST NFs have more light absorption property and red shift, the absence of charge transfer phenomena shows less photocatalysis activity than FeSiNST NFs (Figure 9). $\mathrm{O}_{\mathrm{vs}}$ have great ability to capture electrons, which leads to separating $\mathrm{e}^{-}-\mathrm{h}$, resulting in effective photocatalysis activity. ${ }^{53}$ The creation of $\mathrm{O}_{\mathrm{vs}}$ is because of the presence of $\mathrm{N}$ and $\mathrm{S}$ and $\alpha-\mathrm{Fe}_{2} \mathrm{O}_{3}$. Hence, the availability of $\mathrm{O}_{\mathrm{vs}}$ in FeSiNST NFs (PL and XPS study) supports the efficient photoreduction $\mathrm{Cr}(\mathrm{VI})$, and the photodegradation of 4-NP and phenol. The high photocurrent density enables generation of high electrons and holes which support tremendous 
photocatalysis performance in FeSiNST NFs compared with NST NFs (electrochemical study, Figure 8). The increase of $E_{\mathrm{fb}}$ in FeSiNST NFs has a greater ability for suppressing $\mathrm{e}^{-}-\mathrm{h}$ recombination than NST NFs, resulting in high photocatalysis performance. The small values of $R_{\mathrm{ct}}$ and $W_{\mathrm{s}}$ (EIS study) enhance charge transfer, charge separation, and ion momentum in the case of FeSiNST NFs, resulting in superior photoreduction of $\mathrm{Cr}(\mathrm{VI})$, and photodegradation of 4-NP and phenol compared with other synthesized NFs.

The kinetics of $\mathrm{Cr}(\mathrm{VI})$ photoreduction, and 4-NP and phenol photodegradation, by mesoporous FeSiNST NFs is revealed in Figure $9 \mathrm{~d}-\mathrm{f}$. The outcomes are fitted in $\log C_{0} / C$ vs $t$. Various concentrations $\left(40,50\right.$, and $\left.60 \mathrm{mg} \cdot \mathrm{L}^{-1}\right)$ of $\mathrm{Cr}(\mathrm{VI})$ and the concentrations $\left(30,40\right.$, and $\left.50 \mathrm{mg} \cdot \mathrm{L}^{-1}\right)$ for $4-\mathrm{NP}$ and phenol with time variation $(20,40$, and $60 \mathrm{~min})$ for all are studied in the kinetic process. The rate of photocatalysis performance is more at lower concentrations of $\mathrm{Cr}(\mathrm{VI}), 4-\mathrm{NP}$, and phenol and goes down with a rise of concentration. The concentrations of $\mathrm{Cr}(\mathrm{VI}), 4-\mathrm{NP}$, and phenol with respect to time achieved a linear relationship. First order kinetics is observed for $\mathrm{Cr}$ (VI) photoreduction and for 4-NP and phenol photodegradation. The calculated data are fitted well for first order kinetics, and the equations are as follows.

$$
\begin{aligned}
& \log C_{0} / C=K t / 2.303 \\
& K=\left(2.303 \log C_{0} / C\right) / t
\end{aligned}
$$

where the first order rate constant is referred to as $K$, the $\mathrm{Cr}(\mathrm{VI})$ concentration (initial) is attributed as $C_{0}$, and $C$ stands for the concentration with passage of time $(t)$.

The active species involved in the photoreduction of $\mathrm{Cr}(\mathrm{VI})$ on FeSiNST NFs is examined by the trapping test, which is illustrated in Figure S10a. It is noted that $\mathrm{h}^{+},{ }^{\bullet} \mathrm{OH}, \mathrm{O}_{2}{ }^{--}$, and $\mathrm{e}^{-}$are the reactive species which are involved in photoreduction. The $\mathrm{Cr}(\mathrm{VI})$ photoreduction is decreased less (IPA as scavenger) than the reaction executed without scavenger, which proves negligible participation of $\bullet \mathrm{OH}$ radicals in photoreduction. The photoreduction of $\mathrm{Cr}(\mathrm{VI})$ decreased appreciably by using BQ. Therefore, $\mathrm{O}_{2}{ }^{\bullet-}$ has some role in the photoreduction process. But the $\mathrm{Cr}(\mathrm{VI})$ photoreduction is extremely diminished when DMSO is used as scavenger. That means $\mathrm{e}^{-}$has a great role in the photoreduction of $\mathrm{Cr}(\mathrm{VI})$ to $\mathrm{Cr}(\mathrm{III})$. Categorically, $\mathrm{e}^{-}$plays a vital role in the photoreduction of $\mathrm{Cr}(\mathrm{VI})$ under visible light. Hence, more association of $\mathrm{e}^{-}$in the reaction proves the high separation of $\mathrm{e}^{-}-\mathrm{h}^{+}$. The trapping test for the photodegradation of 4-NP is pictured in Figure $S 10 \mathrm{~b}$. The result shows that the photodegradation percentage is highly decreased when IPA is used as ${ }^{\circ} \mathrm{OH}$ scavenger as compared to other scavengers such as $\mathrm{KI}, \mathrm{DMSO}$, and $\mathrm{BQ}$. Hence, ${ }^{\circ} \mathrm{OH}$ has great role in the 4-NP photodegradation. The photodegradation of phenol will also follow the same trend as that of 4-NP. Conclusively, $\mathrm{e}^{-}$is the active agent for the photoreduction of the $\mathrm{Cr}(\mathrm{VI})$, whereas - $\mathrm{OH}$ is the active agent for 4-NP and phenol photodegradation.

3.7.1. Mechanism of Photocatalysis Activity. Appropriate $\mathrm{CB}$ and $\mathrm{VB}$ of the semiconductors are essential to study the mechanism of the $\mathrm{Cr}(\mathrm{VI})$ photoreduction, and 4-NP and phenol photodegradation. From the MS diagram (Figure $8 b$ ), the $E_{\mathrm{fb}}$ for $\alpha-\mathrm{Fe}_{2} \mathrm{O}_{3} \mathrm{NFs}$ is $-0.61 \mathrm{~V}$ which is nearly equal to the conduction band potential $\left(E_{\mathrm{CB}}\right)$ of the $\alpha-\mathrm{Fe}_{2} \mathrm{O}_{3} \mathrm{NFs} .{ }^{50}$ Hence, the $E_{\mathrm{CB}}$ of $\alpha-\mathrm{Fe}_{2} \mathrm{O}_{3} \mathrm{NFs}$ is $-0.61 \mathrm{eV}$, whereas the $E_{\mathrm{fb}}$ for NST NFs is $-0.78 \mathrm{~V}$ (Figure $8 \mathrm{c}$ ). Hence the $E_{\mathrm{CB}}$ of NST NFs is
$-0.78 \mathrm{eV}$. The calculated band gap, i.e., $2.55 \mathrm{eV}$, is for NST NFs (Figure 5). Hence, the $E_{\mathrm{VB}}$ (valence band potential) will be $1.77 \mathrm{eV}$. Scheme 3 depicts the band edge plot of NST NFs.

Scheme 3. Possible Reaction Mechanism, Charge Separation, and $\mathrm{e}^{-}-\mathrm{h}^{+}$Transfer in Mesoporous FeSiNST NFs

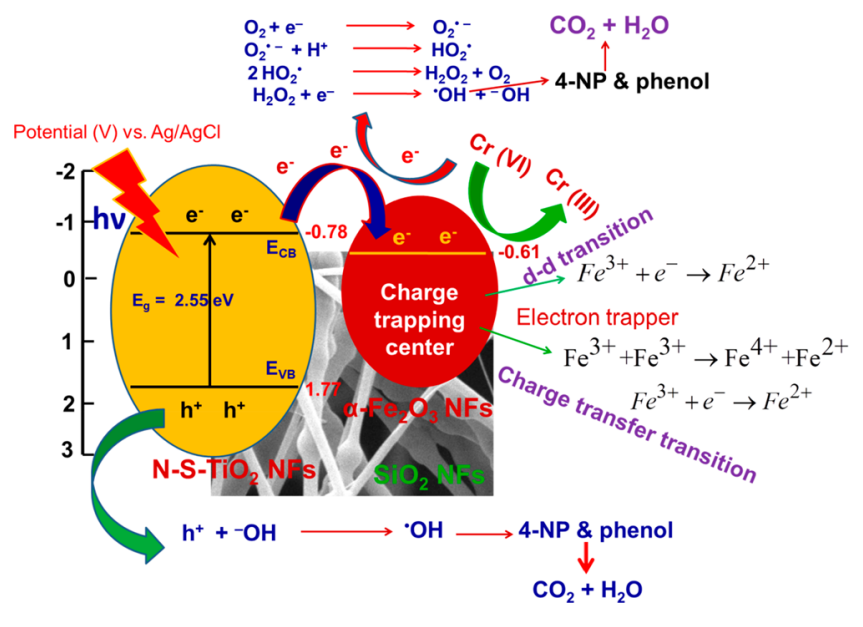

On the irradiation of visible light, the $\mathrm{e}^{-}-\mathrm{h}^{+}$are formed, which are employed in photoreduction and photodegradation processes. In the photocatalysis process, the recombination of $\mathrm{e}^{-}-\mathrm{h}^{+}$hinders the reaction efficiency. To avoid this type of problem, a charge trapper center $\alpha-\mathrm{Fe}_{2} \mathrm{O}_{3}$ which is present in mesoporous FeSiNST NFs enables suppression of the $\mathrm{e}^{-}-\mathrm{h}^{+}$ recombination. The charge trapper phenomenon occurred in both types of transition, i.e., $\mathrm{d}-\mathrm{d}$ transition and charge transfer transition. In the $\mathrm{d}-\mathrm{d}$ transition and charge transfer transition phenomena, the photogenerated electrons are trapped by $\mathrm{Fe}^{3+}$ center (Scheme 3). According to the crystal field theory, the $\mathrm{Fe}$ $\mathrm{d}$-orbitals are vacant during the oxidation/reduction reaction process. Therefore, this process is called the electron trapper process and the $\mathrm{Fe}^{3+}$ in $\alpha-\mathrm{Fe}_{2} \mathrm{O}_{3} \mathrm{NFs}$ (FeSiNST NFs) is called the electron trapper center. Hence, both $\mathrm{d}-\mathrm{d}$ transition and charge transfer transition phenomena are due to the presence of $\alpha-\mathrm{Fe}_{2} \mathrm{O}_{3}$ in the FeSiNST NFs which aids in diminishing the $\mathrm{e}^{-}-\mathrm{h}^{+}$recombination and enhancing the photoreduction of $\mathrm{Cr}(\mathrm{VI})$ and photodegradation of 4-NP and phenol. Hence mesoporous FeSiNST NFs display the highest photocatalysis performance in visible light (Figure 9). From the active species trapping test (Figure S10a), it is examined that the $\mathrm{e}^{-}$is the most active agent for the photoreduction of $\mathrm{Cr}(\mathrm{VI})$. The ${ }^{\bullet} \mathrm{OH}$ is the active agent for the photodegradation of 4-NP and phenol (Figure S10b). Conclusively, efficient separation of $\mathrm{e}^{-}-$ $\mathrm{h}^{+}$has a vital role in the photocatalysis performance.

3.7.2. Recyclability, Stability, and Evidence of $\mathrm{Cr}(\mathrm{VI})$ Photoreduction and 4-NP Photodegradation. The recyclability, stability, and evidence regarding $\mathrm{Cr}(\mathrm{VI})$ photoreduction by FeSiNST NFs are shown in Figure 10, parts a, b, and c, respectively. The recyclability experiment is executed in the optimum condition of the photoreduction of $\mathrm{Cr}(\mathrm{VI})$. After each run is finished, the mesoporous FeSiNST NFs material is calcined at $450{ }^{\circ} \mathrm{C}$ in $5 \mathrm{~h}$ in order to remove impurity and make reborn the mesoporosity. The result is nearly similar up to the fourth consecutive run, indicating the reusability of the mesoporous FeSiNST NFs (Figure 10a). The stability test of mesoporous FeSiNST NFs was examined by the SEM image after $\mathrm{Cr}(\mathrm{VI})$ photoreduction (Figure 10b). The NFs 

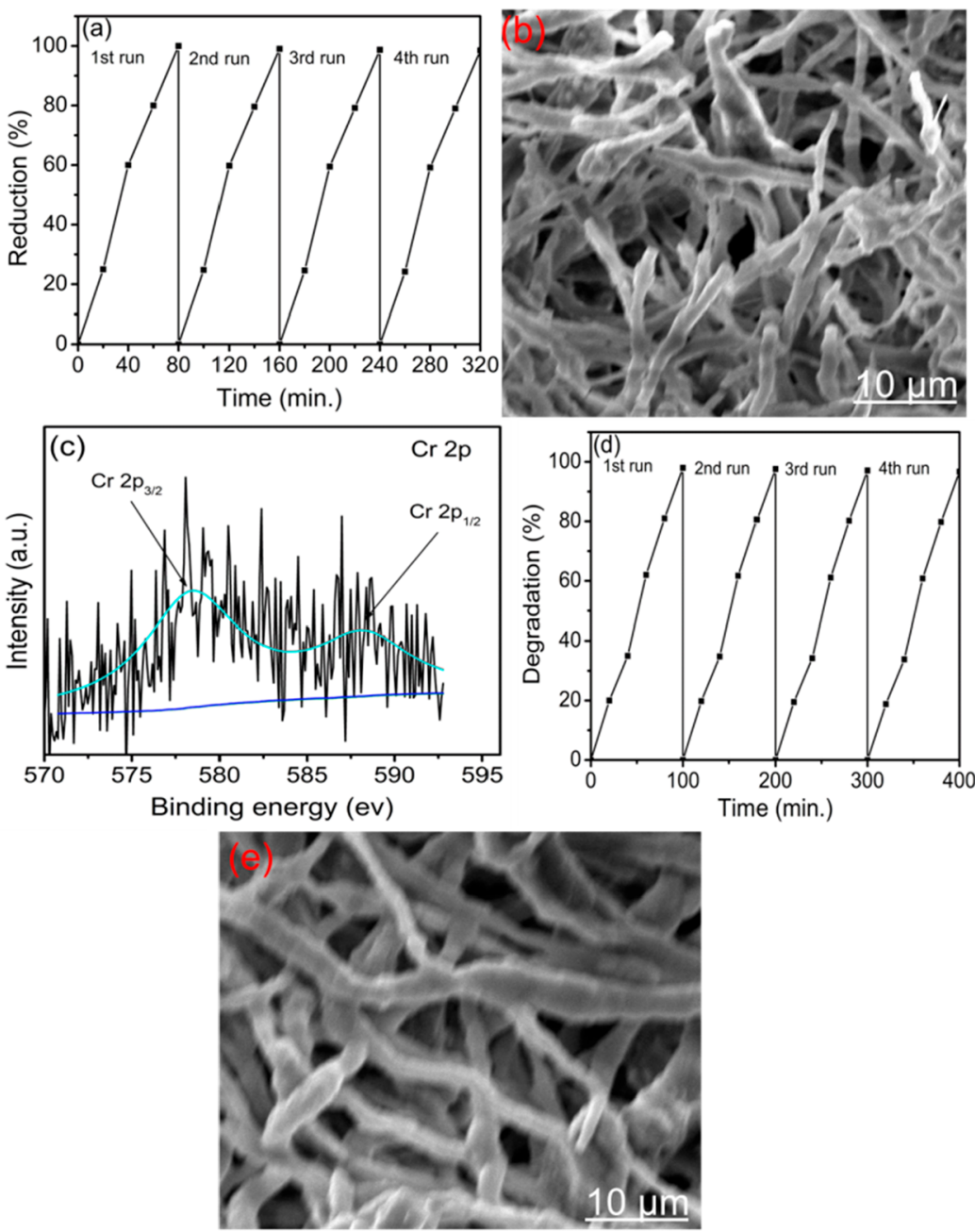

Figure 10. (a) Recycling study, (b) stability, and (c) evidence for photoreduction of $\mathrm{Cr}(\mathrm{VI})$ in optimum condition. (d) Recycling study and (e) stability of 4-NP photodegradation by mesoporous FeSiNST NFs in optimum condition.

morphology is observed in FeSiNST NFs after the photoreduction of $\mathrm{Cr}(\mathrm{VI})$, proving a stable photocatalyst during photoreduction. The $\mathrm{Cr} 2 \mathrm{p}$ spectrum after $\mathrm{Cr}(\mathrm{VI})$ photoreduction on FeSiNST NFs is presented in Figure 10c. The BEs at 579.4 and $586.6 \mathrm{eV}$ are referred to the $\mathrm{Cr} 2 \mathrm{p}_{3 / 2}$ and $\mathrm{Cr}$ $2 p_{1 / 2}$, respectively, which are recommended to the $\mathrm{Cr} 2 \mathrm{p}$ in $\mathrm{Cr}(\mathrm{VI}){ }^{54}$ In Figure 10c, the BEs at $578.2\left(\mathrm{Cr} 2 \mathrm{p}_{3 / 2}\right)$ and 588.2 $\mathrm{eV}\left(\mathrm{Cr} 2 \mathrm{p}_{1 / 2}\right)$ match the $\mathrm{Cr} 2 \mathrm{p}$ in $\mathrm{Cr}(\mathrm{III}){ }^{55}$ This is because of the existence of $\mathrm{Cr}(\mathrm{III})$ after the photoreduction of $\mathrm{Cr}(\mathrm{VI})$ by FeSiNST NFs. This result gives the evidence for complete photoreduction of $\mathrm{Cr}(\mathrm{VI})$ to $\mathrm{Cr}(\mathrm{III})$ during the photoreduction process by FeSiNST NFs. Figure 10d describes the recyclability test of 4-NP photodegradation by FeSiNST NFs. The recyclability test is performed in the optimum condition of the 4-NP photodegradation, and after each run the FeSiNST NFs was calcined at $450{ }^{\circ} \mathrm{C}$ in $5 \mathrm{~h}$. The result shows that the photodegradation of 4-NP is nearly similar up to the fourth run, indicating the versatility and reusability of the FeSiNST NFs. The stability test of FeSiNST NFs is examined by the SEM image after 4-NP photodegradation (Figure 10e). The NFs morphology is observed in FeSiNST NFs after the photodegradation of 4-NP, indicating that the photocatalyst is stable during reaction.

\section{CONCLUSION}

PVP and CTAB template/surfactant mixed method is employed for the synthesis of mesoporosity within NFs in all synthesized NFs photocalysts by the electrospinning via solgel process. Formation of enriched mesoporosity within NFs is the important achievement in terms of morphology control. Mesoporosity within NFs provides superior $S_{A}$, mechanical support, and smooth $\mathrm{e}^{-}$transport, which is the vital approach of the present study. Mesoporosity within NFs enhances the active sites for a proficient photocatalysis performance. The charge transfer phenomenon includes $\mathrm{d}-\mathrm{d}$ transition and charge transfer transition enhancing $\mathrm{e}^{-}$and $\mathrm{h}^{+}$separation effectively. This is the significant reason for an efficient photocatalysis performance. The red shifting and $\mathrm{O}_{\mathrm{vs}}$ within photocatalysts increase the long-range light absorption properties and suppress the $\mathrm{e}^{-}-\mathrm{h}^{+}$recombination, respectively, also having a marvelous role in photocatalysis. It is established that, among all photocatalysts, mesoporous FeSiNST NFs have the highest photocatalytic activity. The recyclability and stability study in $\mathrm{Cr}(\mathrm{VI})$ photoreduction and 4-NP photodegradation support the stability and reusable nature of the FeSiNST NFs photocatalyst. The $\mathrm{Cr}(\mathrm{VI})$ photoreduction to $\mathrm{Cr}(\mathrm{III})$ by FeSiNST NFs is proved by XPS analysis. The increased photocatalysis activity by mesoporous FeSiNST NFs is 
attributed to the $\mathrm{e}^{-}$capture by $\mathrm{Fe}^{3+}$ center in visible light, resulting in increases of $\mathrm{e}^{-}-\mathrm{h}^{+}$separation. The electrochemical study of the NFs supports the proficient photocatalytic activity through $\mathrm{e}^{-}$generation and transport. These above-said features in photocatalysts are key factors for the tremendous photocatalysis performance.

\section{ASSOCIATED CONTENT}

\section{S Supporting Information}

The Supporting Information is available free of charge on the ACS Publications website at DOI: 10.1021/acs.iecr.9b00970.

Fabrication of mesoporous $\alpha-\mathrm{Fe}_{2} \mathrm{O}_{3}$ NFs, band gap calculation, textural properties of NFs photocatalysts, SEM of FeSiNST HNFs and FeSiNST MNPs, $\mathrm{N}_{2}$ adsorption-desorption of FeSiNST HNFs and FeSiNST MNPs, SAED of mesoporous $\mathrm{TiO}_{2}$ NFs and $\mathrm{SiO}_{2}$ NFs, STEM-EDX and UV-vis-NIR DRS spectra of NFs materials, XPS of pure $\mathrm{TiO}_{2}, \mathrm{SEM}$ and EDX analyses of $\alpha$ - $\mathrm{Fe}_{2} \mathrm{O}_{3}$ NFs, effect of $\mathrm{pH}$ on $\mathrm{Cr}(\mathrm{VI})$ photoreduction and 4-NP and phenol photodegradation, percent of $\mathrm{Cr}(\mathrm{VI})$ photoreduction and photodegradation, trapping experiment (PDF)

\section{AUTHOR INFORMATION}

\section{Corresponding Authors}

*E-mail: tu46@cornell.edu (T.U.).

*E-mail: amaresh32@gmail.com (A.C.P.).

ORCID $\odot$

Amaresh C. Pradhan: 0000-0002-6994-3483

Tamer Uyar: 0000-0002-3989-4481

Notes

The authors declare no competing financial interest.

\section{ACKNOWLEDGMENTS}

We are thankful to M. Guler for TEM/STEM measurement.

\section{REFERENCES}

(1) Zhang, S.; Gao, H.; Liu, X.; Huang, Y.; Xu, X.; Alharbi, N. S.; Hayat, T.; Li, J. Hybrid 0D-2D Nanoheterostructures: In Situ Growth of Amorphous Silver Silicates Dots on g-C3N4 Nanosheets for Full Spectrum Photocatalysis. ACS Appl. Mater. Interfaces 2016, 8, 35138.

(2) Kayaci, F.; Vempati, S.; Ozgit-Akgun, C.; Donmez, I.; Biyikli, N.; Uyar, T. Transformation of polymer-ZnO core-shell nanofibers into $\mathrm{ZnO}$ hollow nanofibers: Intrinsic defect reorganization in $\mathrm{ZnO}$ and its influence on the photocatalysis. Appl. Catal. B: Environ 2015, 176177, 646.

(3) Pradhan, A. C.; Nanda, B.; Parida, K. M.; Rao, G. R. Fabrication of the Mesoporous $\mathrm{Fe} @ \mathrm{MnO}_{2} \mathrm{NPs}-\mathrm{MCM}-41$ Nanocomposite: An Efficient Photocatalyst for Rapid Degradation of Phenolic Compounds. J. Phys. Chem. C 2015, 119, 14145.

(4) Priya, M. H.; Madras, G. Kinetics of Photocatalytic Degradation of Chlorophenol, Nitrophenol, and Their Mixtures. Ind. Eng. Chem. Res. 2006, 45, 482.

(5) Nanda, B.; Pradhan, A. C.; Parida, K. M. Fabrication of mesoporous $\mathrm{CuO} / \mathrm{ZrO}_{2}-\mathrm{MCM}-41$ nanocomposites for photocatalytic reduction of $\mathrm{Cr}$ (VI). Chem. Eng. J. 2017, 316, 1122.

(6) Kung, K. H.; McBride, M. B. Bonding of Chlorophenols on Iron and Aluminum Oxides. Environ. Sci. Technol. 1991, 25, 702.

(7) Pradhan, A. C.; Sahoo, M. K.; Bellamkonda, S.; Parida, K. M.; Rao, G. R. Enhanced Photodegradation of Dyes and Mixed Dyes by Heterogeneous Mesoporous Co-Fe/Al2O3- MCM-41 Nanocomposites: Nanoparticles formation, Semiconductor Behavior and Mesoporosity. RSC Adv. 2016, 6, 94263.
(8) Kayaci, F.; Ozgit-Akgun, C.; Donmez, I.; Biyikli, N.; Uyar, T. Polymer-Inorganic Core-Shell Nanofibers by Electrospinning and Atomic Layer Deposition: Flexible Nylon-ZnO Core-Shell Nanofiber Mats and Their Photocatalytic Activity. ACS Appl. Mater. Interfaces 2012, 4, 6185.

(9) Kayaci, F.; Vempati, S.; Ozgit-Akgun, C.; Biyikli, N.; Uyar, T. Enhanced Photocatalytic Activity of Homoassembled $\mathrm{ZnO}$ Nanostructures on Electrospun Polymeric Nanofibres: A Combination of Atomic Layer Deposition and Hydrothermal Growth. Appl. Catal., B 2014, 156-157, 173

(10) Jung, S.; Yong, K. Fabrication of $\mathrm{CuO}-\mathrm{ZnO}$ nanowires on a stainless steel mesh for highly efficient photocatalytic applications. Chem. Commun. 2011, 47, 2643.

(11) Kayaci, F.; Vempati, S.; Ozgit-Akgun, C.; Donmez, I.; Biyikli, N.; Uyar, T. Selective Isolation of Electron or Hole in Photocatalysis: $\mathrm{ZnO}-\mathrm{TiO}_{2}$ and $\mathrm{TiO}_{2}-\mathrm{ZnO}$ Core-Shell Structured Heterojunction Nanofibers via Electrospinning and Atomic Layer Deposition. Nanoscale 2014, 6, 5735.

(12) Vinu, R.; Madras, G. Kinetics of Simultaneous Photocatalytic Degradation of Phenolic Compounds and Reduction of Metal Ions with Nano-TiO 2 . Environ. Sci. Technol. 2008, 42, 913.

(13) Pradhan, A. C.; Senthamizhan, A.; Uyar, T. Electrospun Mesoporous Composite $\mathrm{CuO}-\mathrm{Co}_{3} \mathrm{O}_{4} / \mathrm{N}-\mathrm{TiO}_{2}$ Nanofibers as Efficient Visible Light Photocatalysts. Chem. Select. 2017, 2, 7031.

(14) Pradhan, A. C.; Uyar, T. Morphological Control of Mesoporosity and Nanoparticles within $\mathrm{Co}_{3} \mathrm{O}_{4}-\mathrm{CuO}$ Electrospun Nanofibers: Quantum Confinement and Visible Light Photocatalysis Performance. ACS Appl. Mater. Interfaces 2017, 9, 35757.

(15) Nie, L.; Yu, J.; Fu, J. Complete Decomposition of Formaldehyde at Room Temperature over a Platinum-Decorated HierarchicallyPorous Electrospun Titania Nanofiber Mat. ChemCatChem 2014, 6, 1983.

(16) Abdal-hay, A.; Hamdy Makhlouf, A. S.; Khalil, H. K. A. Novel, Facile, Single-Step Technique of Polymer $/ \mathrm{TiO}_{2}$ Nanofiber Composites Membrane for Photodegradation of Methylene Blue. ACS Appl. Mater. Interfaces 2015, 7, 13329.

(17) Choi, S. K.; Kim, S.; Lim, S. K.; Park, H. Photocatalytic Comparison of $\mathrm{TiO}_{2}$ Nanoparticles and Electrospun $\mathrm{TiO}_{2}$ Nanofibers: Effects of Mesoporosity and Interparticle Charge Transfer. J. Phys. Chem. C 2010, 114, 16475.

(18) Wessel, C.; Ostermann, R.; Dersch, R.; Smarsly, B. M. Formation of Inorganic Nanofibers from Preformed $\mathrm{TiO}_{2}$ Nanoparticles via Electrospinning. J. Phys. Chem. C 2011, 115, 362.

(19) Zhan, S.; Chen, D.; Jiao, X.; Tao, C. Long TiO2 Hollow Fibers with Mesoporous Walls: Sol-Gel Combined Electrospun Fabrication and Photocatalytic Properties. J. Phys. Chem. B 2006, 110, 11199.

(20) Naik, B.; Parida, K. M.; Gopinath, C. S. Facile Synthesis of Nand S-Incorporated Nanocrystalline $\mathrm{TiO}_{2}$ and Direct Solar-LightDriven Photocatalytic Activity. J. Phys. Chem. C 2010, 114, 19473.

(21) Asahi, R.; Morikawa, T.; Ohwaki, T.; Aoki, K.; Taga, Y. VisibleLight Photocatalysis In Nitrogen-Doped Titanium Oxides. Science 2001, 293, 269.

(22) Khan, H.; Swati, I. K. Fe ${ }^{3+}$-doped Anatase $\mathrm{TiO}_{2}$ with d-d Transition, Oxygen Vacancies and $\mathrm{Ti}^{3+}$ Centers: Synthesis, Characterization, UV-vis Photocatalytic and Mechanistic Studies. Ind. Eng. Chem. Res. 2016, 55, 6619.

(23) Nakamura, R.; Okamoto, A.; Osawa, H.; Irie, H.; Hashimoto, K. Design of All-Inorganic Molecular-Based Photocatalysts Sensitive to Visible Light: Ti (IV)-O-Ce (III) Bimetallic Assemblies on Mesoporous Silica. J. Am. Chem. Soc. 2007, 129, 9596.

(24) Pradhan, A. C.; Martha, S.; Mahanta, S. K.; Parida, K. M. Mesoporous nanocomposite $\mathrm{Fe} / \mathrm{Al}_{2} \mathrm{O}_{3}-\mathrm{MCM}-41$ : An efficient photocatalyst for hydrogen production under visible light. Int. J. Hydrogen Energy 2011, 36, 12753.

(25) Sing, K. S. W.; Everett, D. H.; Haul, R. A. W.; Moscou, L.; Pierotti, R. A.; Rouquerol, J.; Siemieniewska, T. Reporting Physisorption Data for Gas/Solid Systems with Special Reference to the Determination of Surface area and Porosity. Pure Appl. Chem. 1985, 57, 603. 
(26) Ji, X.; Lee, K. T.; Nazar, L. F. A Highly Ordered Nanostructured Carbon-Sulphur Cathode for Lithium-Sulphur Batteries. Nat. Mater. 2009, 8, 500.

(27) Pal, M.; Rakshit, R.; Mandal, K. Facile Functionalization of $\mathrm{Fe}_{2} \mathrm{O}_{3}$ Nanoparticles to Induce Inherent Photoluminescence and Excellent Photocatalytic Activity. Appl. Phys. Lett. 2014, 104, 233110. (28) Lopez, R.; Gomez, R. Band-gap Energy Estimation from Diffuse Reflectance Measurements on Sol-Gel and Commercial $\mathrm{TiO}_{2}$ : A Comparative Study. J. Sol-Gel Sci. Technol. 2012, 61, 1.

(29) Naldoni, A.; Allieta, M.; Santangelo, S.; Marelli, M.; Fabbri, F.; Cappelli, S.; Bianchi, C. L.; Psaro, R.; Dal Santo, V. Effect of Nature and Location of Defects on Bandgap Narrowing in Black $\mathrm{TiO}_{2}$ Nanoparticles. J. Am. Chem. Soc. 2012, 134, 7600.

(30) Wang, X.; Yan, Y.; Hao, B.; Chen, G. Biomimetic layer-by-layer deposition assisted synthesis of $\mathrm{Cu}, \mathrm{N}$ co-doped $\mathrm{TiO}_{2}$ nanosheets with enhanced visible light photocatalytic performance. Dalton Trans. 2014, 43, 14054.

(31) Wang, E.; He, T.; Zhao, L.; Chen, Y.; Cao, Y. Improved visible light photocatalytic activity of titania doped with tin and nitrogen. $J$. Mater. Chem. 2011, 21, 144.

(32) Dhlaminia, M. S.; Terblansa, J. J.; Kroona, R. E.; Ntwaeaborwaa, O. M.; Ngaruiyaa, J. M.; Bothab, J. R.; Swarta, H. C. Photoluminescence properties of $\mathrm{SiO}_{2}$ surface-passivated $\mathrm{PbS}$ nanoparticles. S. Afr. J. Sci. 2008, 104, 398.

(33) Liu, K.; Su, C.-Y.; Perng, T.-P. Highly porous N-doped $\mathrm{TiO}_{2}$ hollow fibers with internal three-dimensional interconnected nanotubes for photocatalytic hydrogen production. RSC Adv. 2015, 5, 88367.

(34) Lim, S. P.; Pandikumar, A.; Huang, N. M.; Lim, H. N.; Gu, G.; Ma, T. L. Promotional effect of silver nanoparticles on the performance of $\mathrm{N}$-doped $\mathrm{TiO}_{2}$ photoanode-based dye-sensitized solar cells. RSC Adv. 2014, 4, 48236.

(35) Marcus, R. Chemical and Electrochemical Electron-Transfer Theory. Annu. Rev. Phys. Chem. 1964, 15, 155.

(36) Li, Y.; Wang, Z.; Lv, X.-J. N-Doped $\mathrm{TiO}_{2}$ Nanotubes/N-doped Graphene Nanosheets Composites as High Performance Anode Materials in Lithium-Ion Battery. J. Mater. Chem. A 2014, 2, 15473.

(37) Rodriguez, J. A.; Jirsak, T.; Dvorak, J.; Sambasivan, S.; Fischer, D. J. Reaction of $\mathrm{NO}_{2}$ with $\mathrm{Zn}$ and $\mathrm{ZnO}$ : Photoemission, XANES, and Density Functional Studies on the Formation of $\mathrm{NO}_{3}$. J. Phys. Chem. $B$ 2000, 104, 319.

(38) Fang, J.; Liu, W.; Yu, F.; Qin, F.; Wang, M.; Zhang, K.; Lai, Y. $\mathrm{Fe}, \mathrm{S}$ Co-Doped Anatase $\mathrm{TiO}_{2}$ Nanotubes as Anodes with Improved Electrochemical Performance for Lithium Ion Batteries. RSC Adv. 2016, 6, 70133 .

(39) Ohno, T.; Akiyoshi, M.; Umebayashi, T.; Asai, K.; Mitsui, T.; Matsumura, M. Preparation of S-Doped $\mathrm{TiO}_{2}$ Photocatalysts and their Photocatalytic Activities Under Visible Light. Appl. Catal., A 2004, $265,115$.

(40) Seetharaman, A.; Sivasubramanian, D.; Gandhiraj, V.; Soma, V. R. Tunable Nanosecond and Femtosecond Nonlinear Optical Properties of C-N-S-Doped $\mathrm{TiO}_{2}$ Nanoparticles. J. Phys. Chem. C 2017, 121, 24192.

(41) Morgan, W. E.; Van Wazer, J. R. Binding Energy Shifts in the X-Ray Photoelectron Spectra of a Series of Related Group IV-a Compounds. J. Phys. Chem. C 1973, 77, 964.

(42) Pham, M.-H.; Dinh, C.-T.; Vuong, G.-T.; Ta, N.-D.; Do, T.-O. Visible Light Induced Hydrogen Generation Using A Hollow Photocatalyst with Two Cocatalysts Separated on Two Surface Sides. Phys. Chem. Chem. Phys. 2014, 16, 5937.

(43) Bakar, S. A.; Byzynski, G.; Ribeiro, C. Synergistic effect on the photocatalytic activity of $\mathrm{N}$-doped $\mathrm{TiO}_{2}$ nanorods synthesised by novel route with exposed (110) facet. J. Alloys Compd. 2016, 666, 38.

(44) Bharti, B.; Kumar, S.; Lee, H.-N.; Kumar, R. Formation of Oxygen Vacancies and $\mathrm{Ti}^{3+}$ State in $\mathrm{TiO}_{2}$ Thin Film and Enhanced Optical Properties by Air Plasma Treatment. Sci. Rep. 2016, 6, 32355.

(45) Liu, G. J.; Ye, S.; Yan, P. L.; Xiong, F. G.; Fu, P.; Wang, Z. L.; Chen, Z.; Shi, J. Y.; Li, C. Enabling an IntegratedTantalum Nitride
Photoanode to Approach the Theoretical Photocurrent Limit for Solar Water Splitting. Energy Environ. Sci. 2016, 9, 1327.

(46) Srivastav, A.; Verma, A.; Banerjee, A.; Khan, S. A.; Gupta, M.; Satsangi, V. R.; Shrivastav, R.; Dass, S. Gradient doping-a case study with $\mathrm{Ti}-\mathrm{Fe}_{2} \mathrm{O}_{3}$ towards an improved photoelectrochemical response. Phys. Chem. Chem. Phys. 2016, 18, 32735.

(47) Shen, S.; Zhou, J.; Dong, C.-L.; Hu, Y.; Tseng, E. N.; Guo, P.; Guo, L.; Mao, S. S. Surface Engineered Doping of Hematite Nanorod Arrays for Improved Photoelectrochemical Water Splitting. Sci. Rep. 2014, 4, 6627.

(48) Meng, X. Y.; Qin, G. W.; Li, S.; Wen, X. H.; Ren, Y. P.; Pei, W. L.; Zuo, L. Enhanced photoelectrochemical activity for $\mathrm{Cu}$ and $\mathrm{Ti}$ doped hematite: The first principles calculations. Appl. Phys. Lett. 2011, 98, 112104.

(49) Yang, Y.; Xu, D.; Wu, Q.; Diao, P. $\mathrm{Cu}_{2} \mathrm{O} / \mathrm{CuO}$ Bilayered Composite as a High-Efciency Photocathode for Photoelectrochemical Hydrogen Evolution Reaction. Sci. Rep. 2016, 6, 35158.

(50) Kandi, D.; Martha, S.; Thirumurugan, A.; Parida, K. M. Modification of BiOI Microplates with CdS QDs for Enhancing Stability, Optical Property, Electronic Behavior toward Rhodamine B Decolorization, and Photocatalytic Hydrogen Evolution. J. Phys. Chem. C 2017, 121, 4834.

(51) Hou, H.; Wang, L.; Gao, F.; Wei, G.; Tang, B.; Yang, W.; Wu, T. General Strategy for Fabricating Thoroughly Mesoporous Nanofibers. J. Am. Chem. Soc. 2014, 136, 16716.

(52) Dong, W.; Yen, S.-P.; Paik, J.-A.; Sakamoto, J. The Role of Acetic Acid and Glycerol in the Synthesis of Amorphous $\mathrm{MgO}$ Aerogels. J. Am. Ceram. Soc. 2009, 92, 1011.

(53) Zhang, Y.; Dai, R.; Hu, S. Study of the role of oxygen vacancies as active sites in reduced graphene oxide-modified $\mathrm{TiO}_{2}$. Phys. Chem. Chem. Phys. 2017, 19, 7307.

(54) Yan, L. G.; Yang, K.; Shan, R. R.; Yu, H. Q.; Du, B. Calcined ZnAl- and $\mathrm{Fe}_{3} \mathrm{O}_{4} / \mathrm{ZnAl}$-layered double hydroxides for efficient removal of $\mathrm{Cr}(\mathrm{VI})$ from aqueous solution. RSC $A d v .2015,5,96495$.

(55) Jabeen, H.; Chandra, V.; Jung, S.; Lee, J. W.; Kim, K. S.; Kim, S. B. Enhanced $\mathrm{Cr}(\mathrm{VI})$ removal using iron nanoparticle decorated grapheme. Nanoscale 2011, 3, 3583. 